Research Article

\title{
Experimental Study on Shear Failure Mechanism and the Identification of Strength Characteristics of the Soil-Rock Mixture
}

\author{
Shaorui Sun $\mathbb{D}^{1},{ }^{1}$ Feng Zhu $\mathbb{D}^{2},{ }^{2}$ Jihong Wei $\left(\mathbb{D},{ }^{1}\right.$ Wuchao Wang, ${ }^{2}$ and Huilin Le ${ }^{2}{ }^{2}$ \\ ${ }^{1}$ Professor, Department of Geology Engineering, Hohai University, Nanjing 210098, China \\ ${ }^{2}$ Ph.D. Candidate, Department of Geology Engineering, Hohai University, Nanjing 210098, China \\ Correspondence should be addressed to Shaorui Sun; sunsrhhu@163.com and Feng Zhu; 160211090004@hhu.edu.cn
}

Received 22 April 2019; Accepted 24 June 2019; Published 11 July 2019

Academic Editor: Yuri S. Karinski

Copyright (c) 2019 Shaorui Sun et al. This is an open access article distributed under the Creative Commons Attribution License, which permits unrestricted use, distribution, and reproduction in any medium, provided the original work is properly cited.

Soil-rock mixture (SRM) is a special geological material that has the unique properties of rock or soil. Studies on the strength characteristics of the SRM have very important theoretical significance and practical value. In this study, the gravel proportions, gravel sizes, gravel shapes, and repetitive results of shear experiments are considered in laboratory experiments and for the identification of strength parameters. To the gravel shapes, from the angle of the composition materials of SRM, the experimental samples include samples with breccia gravels and with subrounded gravels. And, in this study, the laboratory model experiment is used to research the strength characteristics of SRM. In addition, the shear failure mechanism is used to establish the relationship between the microfailure mechanism and the macrostrength parameters identification. Taking gravel proportion, gravel size, gravel shape, and repetitive shear process as the influencing factors of the SRM, the laboratory models have been remolded, and laboratory direct shear experiments have been carried out. The shear deformation laws of the SRM are researched on the basis of the analysis of the curves of shear stress and the horizontal displacement.

\section{Introduction}

As a heterogeneous geomaterial, the SRM is widely distributed in geological engineering projects (Figure 1). In the southwestern part of China, according to an investigation, the slope consisting of the SRM in the Three Gorges Reservoir occupies $6.8 \%$ of the entire coastline, $12.5 \%$ of the reservoir area, and $8.7 \%$ of the total reservoir capacity. Lots of accumulated slopes distributed widely in the area of the Yalong River, the Lancang River, and the Jinsha River. In addition, the SRM is widely distributed all over the world (Figure 1(b)). Therefore, special strength characteristics of the SRM have important theoretical significance and practical value. The SRM is a kind of nonuniform material and apparent structural feature. So, the strength characteristics of SRM are different from soil or rock, resulting in differences of slope deformation. The mechanism of deformation and strength characteristics are considered as main research content in the stability of soil-rock engineering. Recently, to the slopes consisting of SRM, the parameters of shear strength are given with differences, and the deformation mechanism is studied by few researchers. The selection of parameters is usually nonstandard, so that the deformation mechanism and the parameters of strength should be considered completely with a variety of systemic laboratory and numerical experiments.

Lots of works have been conducted by researchers around the world to study the shear properties and strength characteristics of SRM [1]. The gravels, soil particles, and voids are the main contents of rock-soil mixture [2]. The size and quantity of gravel and the strength of soil part are also important to affect the whole rock mass system. The methods of statistical and numerical modeling have been also used to study the structural distribution and seepage properties of rock-soil [3-5]. The structural properties such as gravel size, rock dimension, and shape are considered in microscopic model [6-10].

Chen [11] conducted a large number of triaxial experiments and field experiments of the SRM, and the block shear and friction holding-on action between the coarse grains on the shear section may have affected the test results. Guo [12] has researched the separate influences of the 

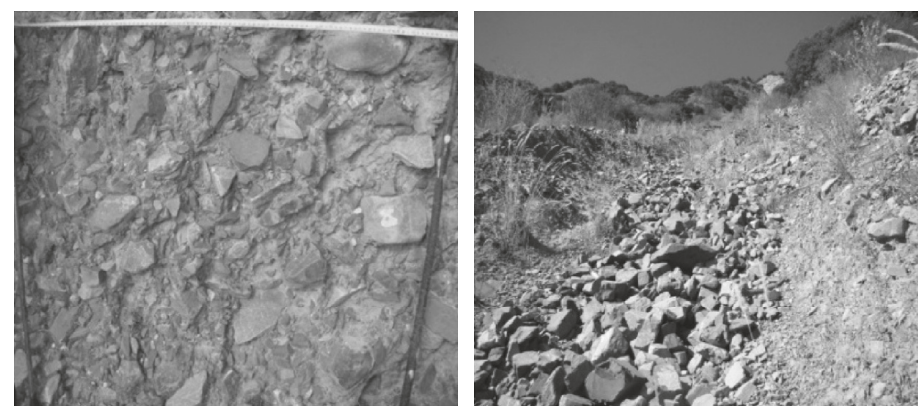

(a)
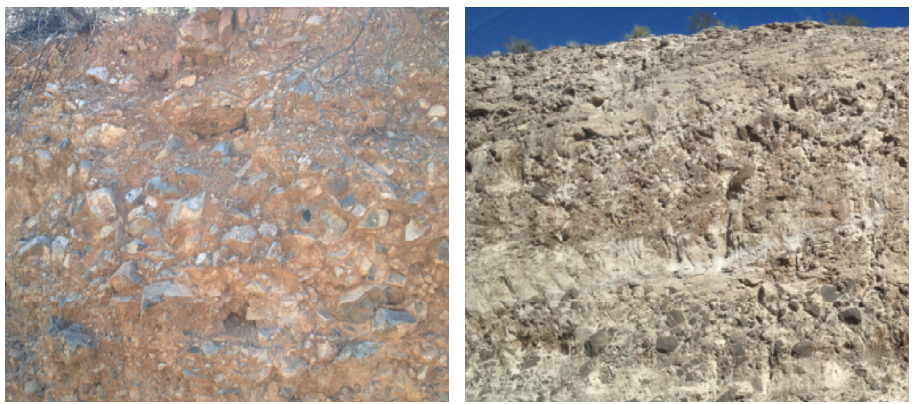

(b)

FIGURE 1: SRM in the field. (a) SRM in southwestern China. (b) SRM in southwestern USA.

fine grains and coarse grains in the SRM on the shear strength and obtained the threshold value of the influence of the coarse grains on shear strength. Miller and Sowers [13] discovered that the shear strength would increase significantly when the content of the coarse grains had reached 50\%-70\%, while the cohesion of the SRM would present a decreasing trend. Patwardhan et al. [14] studied the shear parameters of rocksoil are affected by gravel distribution, and the gravel proportion being $40 \%$ is a threshold. The gravel proportion of $0-40 \%$ has an increasing trend for shear strength. Savely [15] conducted large-scale field experiments and concluded that the shear parameters will increase with gravel proportion increasing. Wu [16] determined by experimental research that the strength of SRM will be affected by the fine grain when the content of coarse grains is less than $40 \%$, by both fine and coarse grains when the content of the coarse grains is $40 \%-70 \%$, and by the coarse grain when the content of coarse grains is more than $70 \%$. Huang et al. [17] have concluded that the stress-strain curve of the SRM, which is in approximate accordance with the Duncan-Chang model, is a nonlinear hardening pattern and that volumetric strain presents the shear contraction. Han et al. [18] obtained the unconfined compression strength of the SRM by using a bearing capacity experiment and the creep laws of the SRM by using compressive creep experiments. Ren et al. [19] evaluated the shear properties of soil-rock mixture considering the rock size effect by a systematic method.

Presently, although certain experimental studies have been conducted by researchers around the world, scientists investigating the failure mechanism and the identification of the SRM by use of experiment have lacked comprehensive and systematic data. Because the grain shape and grain size, the mechanical properties, and arrangement patterns have many differences from those of rock or soil, the failure mechanism is not researched comprehensively. At the same time, the original sample preparation of the SRM is limited by the disturbance condition, sample size, and sample state. It causes the random model of the SRM difficulty in keeping the same between the specimens of field and remold. To avoid these drawbacks, certain researchers have begun to research the strength of the SRM using numerical modeling method. But most of the numerical modeling software requires the adoption of the specific constitutive model, which can affect one's judgment of the failure mechanism of soilrock.

Therefore, laboratory model experiments are still an efficient way to understand the properties of the SRM. With respect to past research, it can be observed that most of the works focus on the influences of gravel content on the failure mechanism of SRM and ignore the influence of gravel size and gravel shape. In fact, strength properties of soil-rock mixture depend not only on gravel proportion but also on other factors, such as the gravel size, the gravel shape, and the experimental conditions. In addition, the properties and characteristics of the SRM will be changed under the conditions of multitime physical action and tectonic action. Thus, repetitive shear experiments for the SRM should be carried out to research the change laws of deformation and the failure mechanism when the change in the structure of the SRM takes place. At the same time, to be available for specific engineering projects, the identification of the strength parameters for the SRM is a necessary undertaking, utilizing the results of the model experiments that consider many influencing factors. 
In this study, the laboratory model experiment is taken to research the shear failure mechanism of SRM, and the identification of the strength characteristics is conducted. In addition, four influencing factors, which are gravel proportion, gravel size, gravel shape, and repetitive shear process, are considered during the construction of the remold samples and the direct shear experiment and for the identification of the shear strength parameters. Furthermore, the change laws of the deformation and strength parameters are researched simultaneously.

\section{Experimental Studies on the Shear Failure Mechanism of the SRM}

\subsection{Direct Shear Experiment of the SRM}

\subsubsection{Experimental Schemes}

(1) Materials preparation. In the process of the laboratory experiments, all the influencing factors, such as the gravel proportion, the gravel size, the gravel shape, and the fine silty clay, are quantified to prepare different samples. To decrease the variation of the selected material and to guarantee the veracity of the experimental results under similar conditions, the gravels are selected with similar physical and mechanical properties. Meanwhile, the gravels include breccia gravels and subrounded gravels.

(1) Soil preparation: the SRM consists of gravels and soil. In this experiment, silty clay is selected as the fine soil. The silty clay is dried outdoors. The aggregate soil is crushed down (Figure 2(a)), and the soil with a grain size of more than $3 \mathrm{~mm}$ is separated (Figure 2(b)). The prepared soil is divided into three parts to meet the requirement of the different types of experiments. The physical parameters of the soil are obtained by conventional indoor experiments, before the SRM laboratory experiments (Table 1).

(2) Gravel preparation: the gravels were collected from the same engineering zone. The density of gravels is $2.43 \mathrm{~g} / \mathrm{cm}^{3}$. The gravels were separated based on the sizes and shapes. In this experiment, the gravel shapes include breccia gravel (BG) and subrounded gravel (SG). Figure 3 shows the gravel preparation and quantization of gravel stone and soil. According to the gravel sizes, the gravels with different shapes are separated into four sets, and the range of the grain size for the sets is $5 \mathrm{~mm}-10 \mathrm{~mm}, 10 \mathrm{~mm}-20 \mathrm{~mm}$, $20 \mathrm{~mm}-30 \mathrm{~mm}$, and $30 \mathrm{~mm}-40 \mathrm{~mm}$ (Figure 3(a)).

(2) Experimental samples preparation. The samples with different gravel proportions are prepared under conditions of the same gravel size and gravel shape. The types of gravel proportion include four sets, which are $10 \%, 30 \%, 50 \%$, and $70 \%$ sets. In the process of sample preparation, the weight of the gravel and soil is separately calculated and measured using the electronic scale according to the volume of the shear box. The number of samples for each experiment is 3 to
5 , and the value is obtained based on the average value of the experiment that is conducted 3 to 5 times. The samples with different gravel sizes are remolded under conditions of the same gravel proportion and gravel shape. The samples based on the gravel sizes are divided into four sets, including 5$10 \mathrm{~mm}, 10-20 \mathrm{~mm}, 20-30 \mathrm{~mm}$, and $30-40 \mathrm{~mm}$ sizes. Two types of gravel shapes, the breccia gravels and subrounded gravels, are considered under conditions of the same gravel proportion and gravel sizes. The process of remolding samples is similar to that of the samples with different gravel proportions. Therefore, from the viewpoint of the composition of materials, there are two types of samples, the sample with breccia gravels (SBG) and the sample with subrounded gravels (SSG).

\subsubsection{Experimental Processes}

(1) Mixture and remolding of the sample. To avoid the loss and cementing of the soil and gravels in the process of the sample mixing, the mixing of the soil and gravels is conducted on a water-proof and smooth cushion (Figure 4(a)). At the same time, the samples are placed into the polyethylene bag before they are placed into the shear box in case fine grain leaks from the shear box during the direct shear experiment (Figure 4(b)). The samples are filled uniformly into the shear box and vibration compacted using the vibrating table. The size of the shear box is $15 \mathrm{~cm} \times 15 \mathrm{~cm} \times 15 \mathrm{~cm}$. Additionally, the samples in the shear box meet the requirement of the gravel proportion. After dispensing the SRM into the shear box, the upper cover board of the shear box is installed (Figure 4(c)).

(2) Process of the direct shear experiment. All shear experiments are conducted by using the direct shear instrument with specification YDS-2. Because the strength parameters of the SRM depend completely on the ratio of the soil and gravels of the shear plane (zone), and as the gravels are distributed randomly in the samples, the deformation and shear parameters of the SRM with the same sets may have greater differences in value. To avoid the differences above, the direct shear experiment for each sample with the same experimental conditions is performed 3 to 5 times. The normal stress, which is $73.17 \mathrm{kPa}, 107.36 \mathrm{kPa}, 141.56 \mathrm{kPa}$, and $180.54 \mathrm{kPa}$, is exerted for every set of samples. As far as each sample is concerned, at the beginning of the experiment, normal stress is exerted on the sample. A horizontal push force is exerted when the sample is under the conditions of a certain normal stress and in the stability state. In the process of the experiment, the final displacement is recorded when there is no displacement taking place for every grading load. The experiment will not be stopped until the displacement presents a continuous increase under a certain shear stress. After the experiment is completed, the normal stress is unloaded firstly and followed by the unloading of horizontal stress. The failure plane of the SRM is cleaned, and a photo is taken to analyze the arrangement patterns of the gravels on the failure plane. After all of the experiments are finished, the experimental results are 


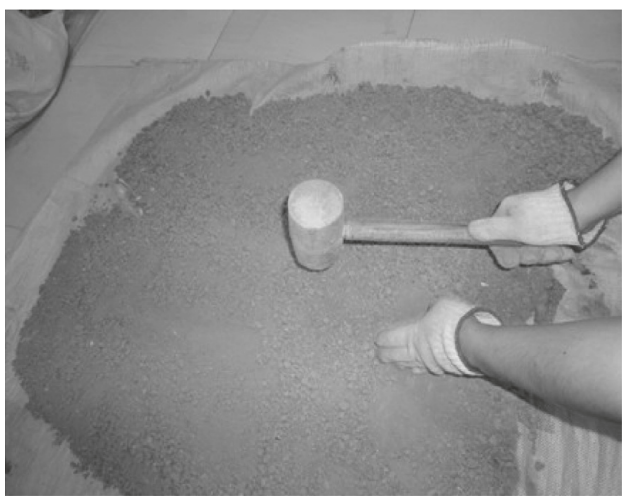

(a)

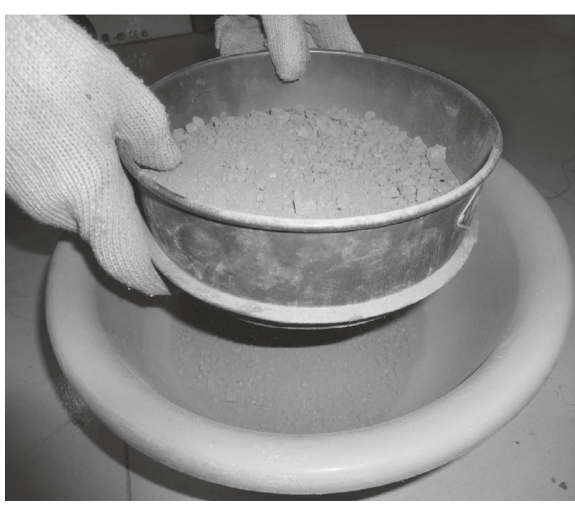

(b)

FIgURE 2: Soil preparation. (a) Crushing down the soil. (b) Sieving soil.

TABle 1: Physical parameters of the soil.

\begin{tabular}{lcccccc}
\hline $\begin{array}{l}\text { Physical parameters of } \\
\text { the soil }\end{array}$ & $\begin{array}{c}\text { Natural density } \\
\left(\mathrm{g} \cdot \mathrm{cm}^{-3}\right)\end{array}$ & $\begin{array}{c}\text { Natural water } \\
\text { content }(\%)\end{array}$ & $\begin{array}{c}\text { Liquid limit } \\
(\%)\end{array}$ & $\begin{array}{c}\text { Plasticity } \\
\text { index }\end{array}$ & $\begin{array}{c}\text { Optimum water } \\
\text { content }(\%)\end{array}$ & $\begin{array}{c}\text { Maximum dry density } \\
\left(\mathrm{g} \cdot \mathrm{cm}^{-3}\right)\end{array}$ \\
\hline & 1.56 & 10.8 & 33.5 & 16.7 & 14.6 & 1.73 \\
\hline
\end{tabular}

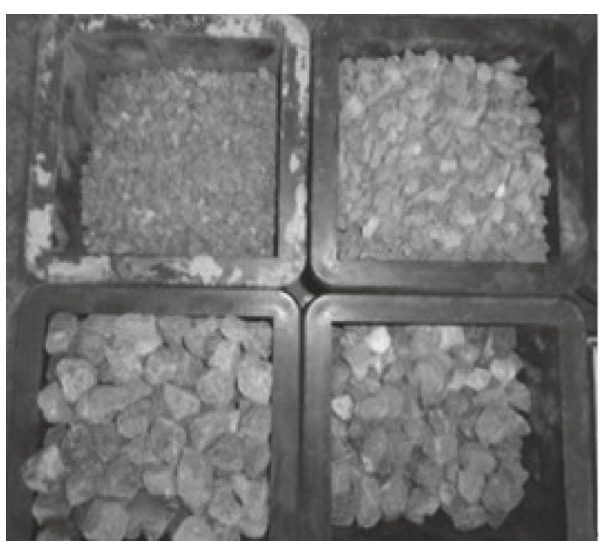

(a)

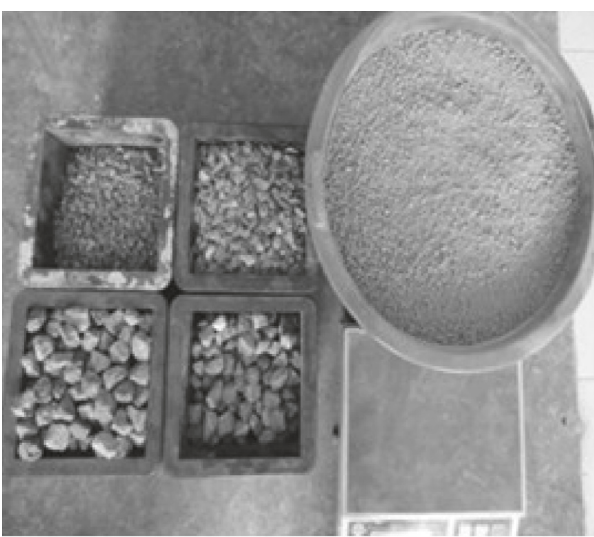

(b)

FIGURE 3: Gravel preparation and quantization of gravel stone and soil. (a) Gravel with different grain sizes. (b) Quantization of gravel stone and soil.

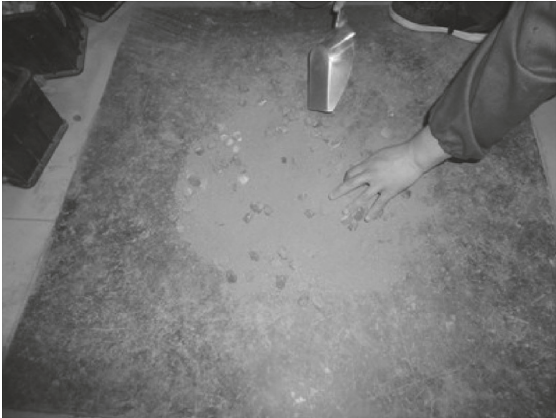

(a)

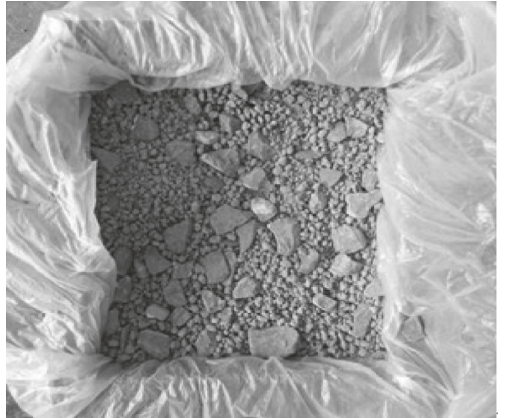

(b)

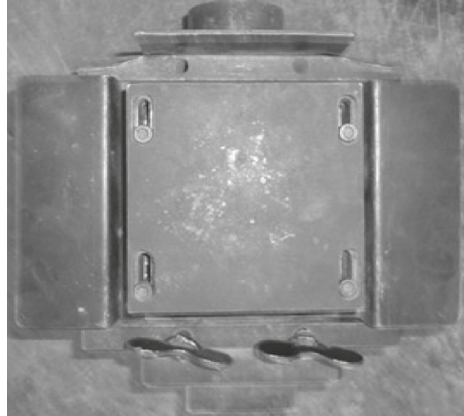

(c)

FIGURE 4: The SRM sample preparation. (a) Mixing soil and gravel. (b) Remolding SRM sample. (c) Placing the SRM sample into the shear box. 
processed and analyzed based on the curve of stress and displacement, the photos of the failure plane, etc.

\subsection{Analysis on Shear Failure Mechanism of the SRM}

2.2.1. Deformation Properties of the SRM. The change curves of shear stress against horizontal displacement are determined by the shear experiments and are displayed in Figure 5. According to Figure 5, four stages are obtained from the curve of shear stress versus horizontal displacement, including the compaction stage with a displacement of $0-1.5 \mathrm{~mm}$, a linear stage with a displacement of $2.0-6.0 \mathrm{~mm}$, an elastic-plastic stage with a displacement of $6.0-8.0 \mathrm{~mm}$, and a plastic-failure stage with a displacement of over $8.0 \mathrm{~mm}$. The horizontal displacements of the sample failure point in the curve for the SBG and SSG become smaller with the increase in the normal stresses. The corresponding shear stresses also increase gradually with the increase in the normal stresses. The initial stage of the curve becomes steep, i.e., the increased ratio of the strain and stress is great, and the strain of the sample becomes small. The curve types of the shear stress and the horizontal displacement present stress hardening. For the SBG, there are great differences in the shear stress under the different normal stress when the value of the horizontal displacement is the same for the different samples. Specifically, there is a great stress difference among the shear stress and the horizontal displacement. Compared to those of the SBG, the differences in the shear stress are small for the SSG. The reason for this small difference can be explained by the compaction role of the SBG being more than that of the SSG, with the normal stress increased during the process of the experiment. From the angle of the gravel proportion and the normal stress, the curves of the shear strength and the horizontal displacement for the samples with a low gravel proportion are more dispersed than that for the samples with a high gravel proportion. Compared to those of the SBG, the curves of the shear strength and horizontal displacement for the SSG exhibit more concentricity. Under the conditions of shear strength, the horizontal displacement for the SSG is greater than that for the SBG. The slope of the linear stage for the SSG is lower than that for the SBG. However, the displacement value of the linear stage for the SBG is lower than that for the SSG. This indicates that the SBG experiences an adjustable process during the shear experiment. This phenomenon is apparent when the gravel proportion is low.

The reasons why the shear stress curve has these characteristics are as follows: (1) The nonuniform coefficients of the SRM are greater than that of the soil and rock because of greater difference for both the soil grains and the gravel grains. The large nonuniform coefficient will easily allow the soil grain to enter into the pores of the coarse gravel grains. Therefore, it can cause the SRM to form a good frame structure. However, the structure of the SRM is loose due to the remolding of the samples. This can cause the shear contraction phenomenon and great deformation of the SRM at the initial stage of the experiment. With the development of the shear experiment, the SRM can become compacted gradually, and the shear stress increases notably. The shear stress and deformation curves change the stress hardening curve. This phenomenon becomes particularly obvious when the normal stress is great. (2) Because the discrete SRM is composed of coarse grain gravel and fine grain soil, the strength of the SRM consists of (i) the intergranular friction force and the intergranular locking force among the coarse grain gravel and (ii) the cohesion between the coarse grain gravel and the fine grain soil. After normal stress is exerted, the SRM experiences a physical process, i.e., the transition from a loose state to a compaction state. Thus, the aforementioned interaction forces coexist in the SRM and exert their influences at the same time, which will lead to the increase of strength in the shear plane. With the shear experiment development, the cohesions, friction forces, and parts of the locking forces among the coarse grain gravels will no longer exert the greatest influence. The big coarse grain gravel will not move with the fine grain soil, which indicates that the shear strength in the shear plane is mainly due to the coarse grain gravel. Lastly, all of the interaction forces among the soil and gravel will loosen, and the sample of the SRM will be damaged along the shear plane (zone).

\subsubsection{Influence of the Gravel Proportion on the Shear Failure} Mechanism. The gravel proportion is a crucial factor that affects the strength properties of soil-rock mixture. Taking a sample with a gravel size of $5-10 \mathrm{~cm}$ as an example, the deformation laws of the SRM with different gravel proportions under different normal stress and gravel shape are displayed in Figure 6. Based on the results of the experiment, it can be observed that there are many differences in the change trend of the shear stress. The horizontal displacement for samples with a gravel proportion of $10 \%$ appears to be the maximum value under the same normal stress when the sample reaches the yield point, while the shear stress emerges as the minimum value. The change laws of the curves will develop opposite to the aforementioned laws as the gravel proportion increases. This change phenomenon can be observed notably for the SBG. Compared with the differences of the curve among the different gravel proportions for the SSG, the changes of the SBG are small. For the SSG, the shear strength of the SRM is the smallest for all samples. The internal friction angle of the sample with a gravel proportion of $70 \%$ is the largest, and the shear strength is also affected by the decrease in the cohesion while the sample with gravel $70 \%$ has a largest internal friction angle. Compared to the SSG, although the shear strength of the SBG also appears to be decreasing to a certain degree, the decreasing magnitude of the shear strength is less than that of the SSG. According to the curve, the differences in the shear strength of the SBG are greater than those of the SSG under the different gravel proportions. Similarly, for the SBG and SSG, the differences in shear strength under the low normal stress are greater than those under the high normal stress. The hardening degree of the SBG is higher than that of 

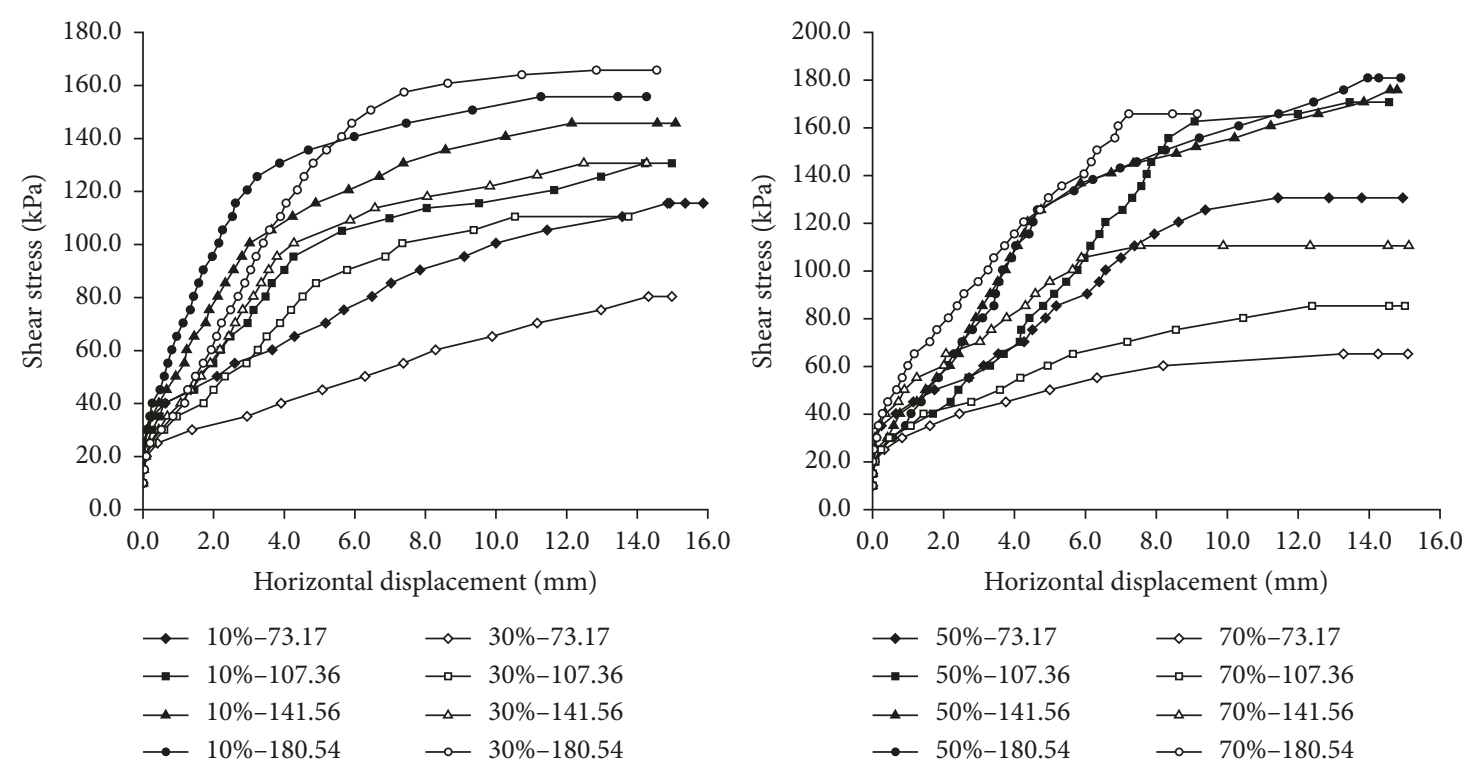

(a)
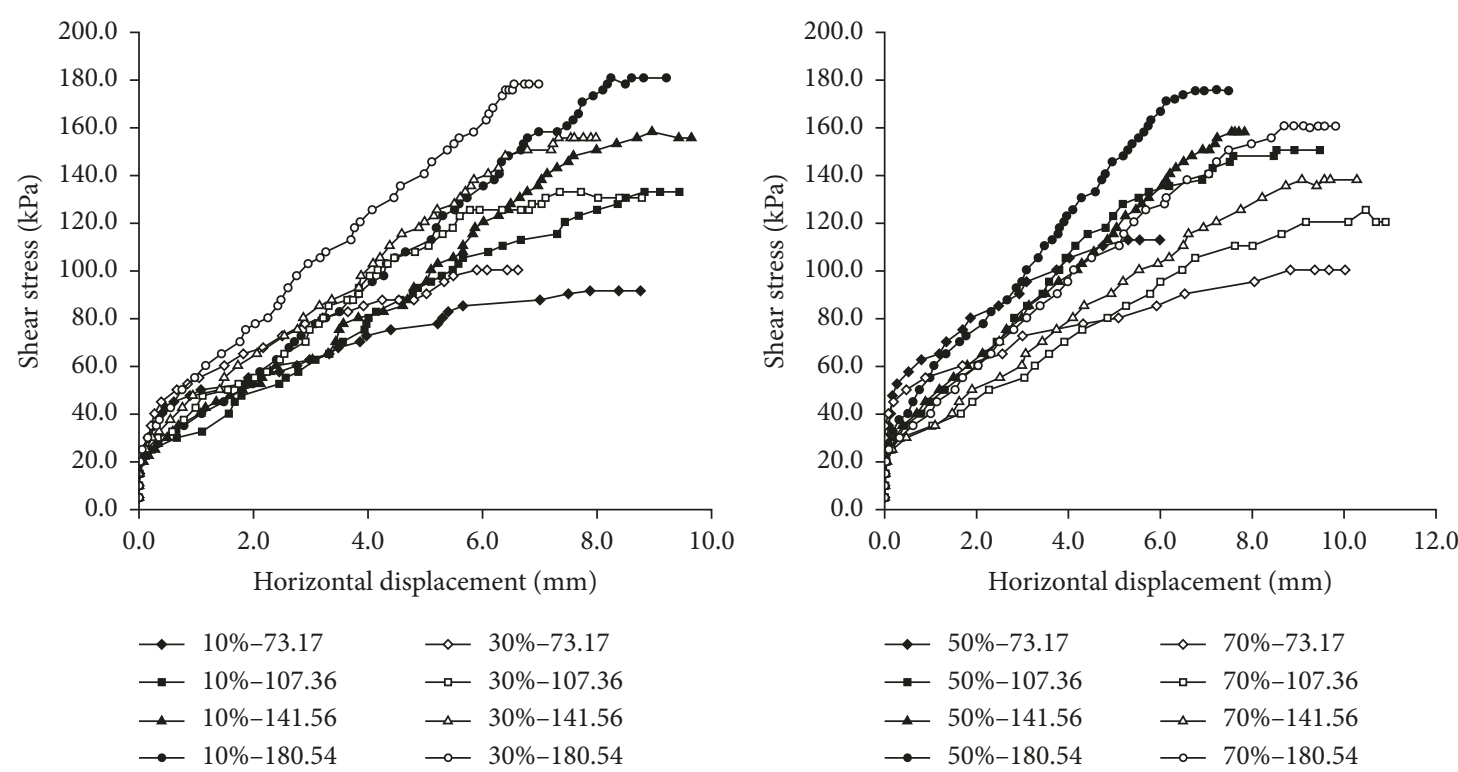

(b)

Figure 5: The curve of the shear stress and horizontal displacement under the different normal stress (GP: gravel proportions; GS: gravel sizes; GSP: gravel shapes; NS: normal stress). (a) SBG. (b) SSG.

the SSG. Briefly, the aforementioned differences in shear strength indicate that the sensitivity of the shear strength in terms of the gravel proportion of the SSG is less than that of the SBG. In addition, it can be observed from Figure 6 that there are many changes characterized by the " $V$ " shape in the curves, especially for the samples with a gravel proportion of $50 \%$ and $70 \%$. Compared with the SBG, the probability of the emergence of this change is very high for the SSG. In the previous study, the shear strength would increase significantly when the content of the coarse grains had reached $50 \%-70 \%$. However, in this paper, the shear strength increases significantly when the gravel proportion reaches $30 \%-50 \%$, and when the gravel proportion is $70 \%$, the shear strength of SRM sample is almost the lowest under the same normal stress, which means the shear strength of SRM is also influenced by many other factors, not completely by the gravel proportion.

The reasons why the curves of shear stress versus horizontal displacement have these characteristics are as follows: (1) The coarse gravels in the samples with a lower gravel proportion are surrounded by the fine soil in the SRM, which fails to form the framework for the gravels. When the gravel proportion increases gradually, the interaction of the coarse gravels makes the shear strength of the SRM increase markedly. Shear strength is supported by coarse gravel, and its horizontal displacement is smaller than the one with a 

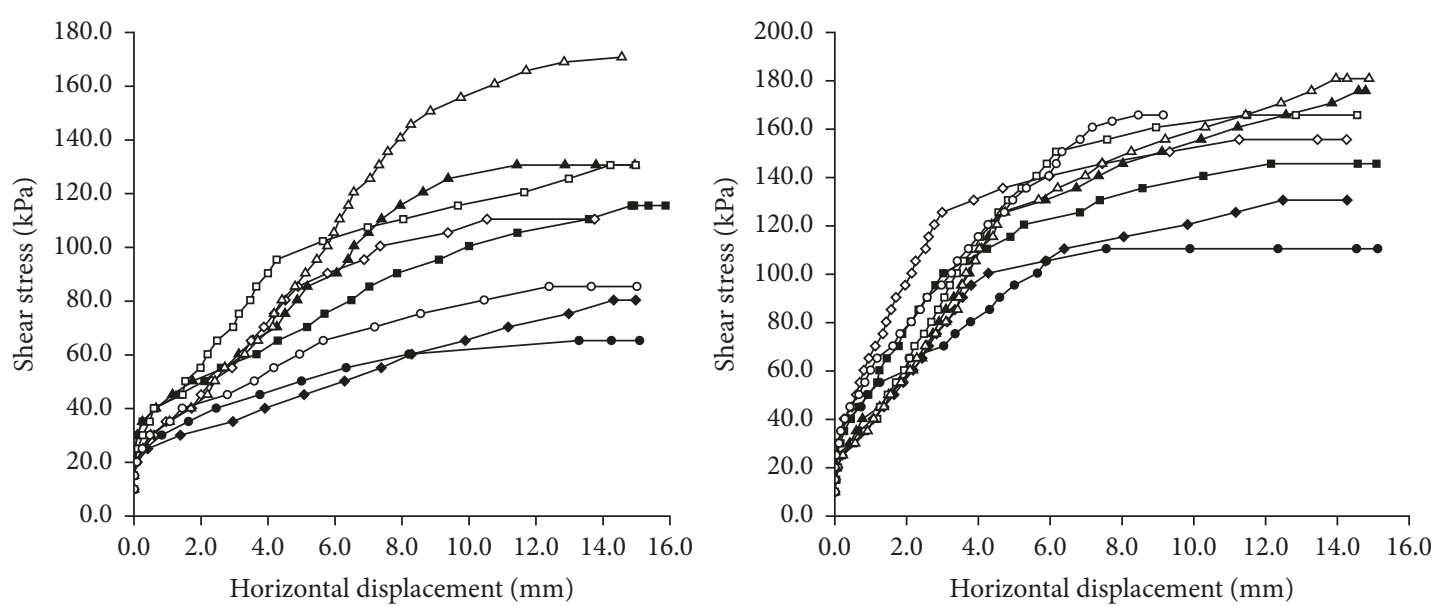

$$
\begin{aligned}
& \rightarrow 73.17 \mathrm{kPa}-10 \% \rightarrow 107.36 \mathrm{kPa}-10 \% \\
& \rightarrow 73.17 \mathrm{kPa}-30 \% \quad \rightarrow-107.36 \mathrm{kPa}-30 \% \\
& \_73.17 \mathrm{kPa}-50 \% \quad \triangle-107.36 \mathrm{kPa}-50 \% \\
& \text { • } 73.17 \mathrm{kPa}-70 \% \quad \multimap 107.36 \mathrm{kPa}-70 \%
\end{aligned}
$$

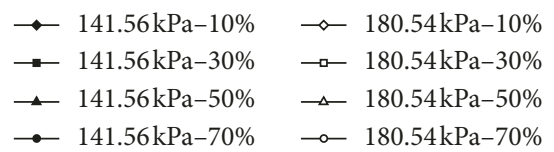

(a)
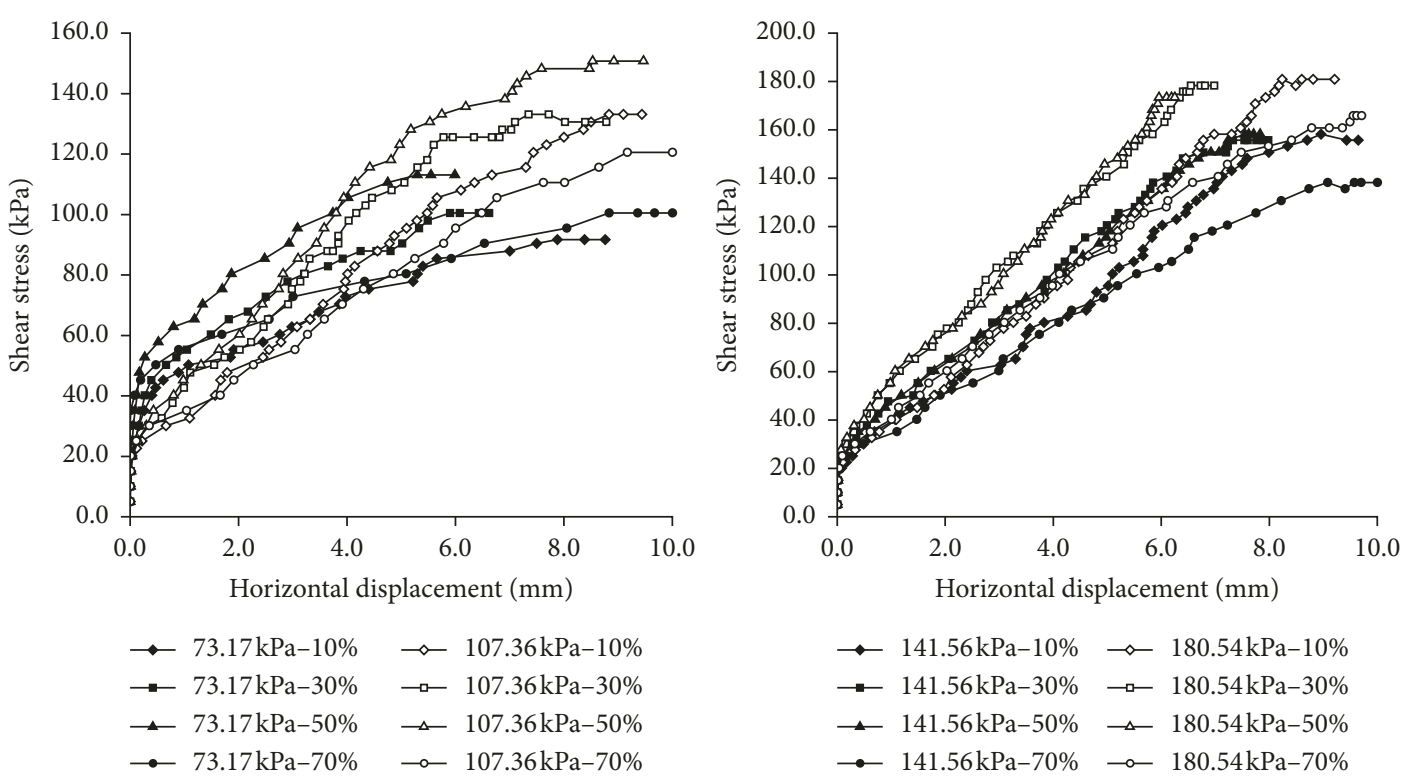

(b)

FIgURE 6: The curve of shear stress versus horizontal displacement with different gravel proportions. (a) SBG. (b) SSG.

smaller gravel proportion. But its shear strength does not increase with the gravel proportion increasing, but begins to decrease when the gravel proportion reaches a certain value, i.e., the "optimal gravel proportion". The mosaic and occlusion actions among the coarse gravel in the SBG are more pronounced than that in the SSG, which leads to small differences in the shear stress emerging among the different samples under the same gravel proportions. (2) The result that the "V"-shaped jumping emerges clearly in the curve of shear stress versus horizontal displacement for samples with a higher gravel proportion indicates that the mosaic and occlusion actions among the gravels are important in the increase of the shear strength. With a higher gravel proportion and higher normal stress, the interaction between the gravel and soil in the initial experimental stage makes the sample more compact, and the stress concentration emerges in the contact parts among the gravels. The gravels in the state of occlusion in the SRM begin to exhibit diastrophism and the roll phenomenon, which makes the shear stress suddenly release and decease. This phenomenon can perfectly explain the jumping phenomenon in the shear stress and horizontal displacement. In addition, the occlusion action for the SSG is lower than that for the SBG, and its degree of stress concentration is small, and the adjustability between the subrounded gravels is perfect under the same shear stress. Thus, the degrees of change in the curve of shear stress versus horizontal displacement for the SSG are less than those of the SBG. 
2.2.3. Influence of Gravel Size on Shear Failure Mechanism. To research the influence of gravel size, the samples with a gravel proportion of $10 \%$ are selected as examples, which can avoid the adverse influence of the compaction between gravels on the shear behavior. Moreover, even though SRM mainly refers to the geologic body with $30 \%-70 \%$ gravel proportion, there are many areas with $10 \%$ gravel proportion on actual engineering slopes. The deformation laws of the SRM with different gravel sizes under different normal stress and gravel shape are displayed in Figure 7. The scope of the gravel sizes can be found in Experimental samples preparation of Section 2.1.1 in this study. According to Figure 7, the horizontal displacements of the samples in the first set and the fourth set have the maximum value under the same normal stress when the sample reaches the yield state. The shear stresses corresponding with the horizontal displacements have the minimum value. The shear stress versus horizontal displacement corresponding with the yield point in the curve fail to exhibit the increasing trends or decreasing trends with the increasing gravel sizes. The maximum value of the shear stress for most of the samples usually emerges in the second set and the third set. For the SSG, the change of shear stress for different sets of specimens intersects under a high gravel proportion and high normal stress. The interval of different curves is closed. That is, the influence of gravel size on shear stress for the SSG is not notable. Compared to the sensitivity of the shear strength in terms of the gravel size for the SSG, the sensitivity of the SBG is large. The hardening degree of the SBG is far greater than that of the SSG. The change of shear stress has several "V"shaped jumps for the first set and second set samples, especially for the samples with a high gravel proportion and low normal stress. The curves of shear stress versus displacement become closer to each other under conditions of high normal stress.

Based on the aforementioned analysis, when the gravel size is small (10\% gravel proportion), it is difficult for the gravels to come into contact with each other, even if there is a great deal of gravels in the SRM. It causes the shear strength to undergo minimal change because the shear strength is afforded mainly by the fine grain soil. Simultaneously, the amount of gravel is very little when the gravel size is large. It can cause the shear strength to decrease due to the minimal amount of contact between the gravels. The shear zone in the SRM consists of the fine grain soil, and the shear strength of the SRM is similarly afforded by the fine grain soil. Only when the proportion between the coarse gravel and fine soil reaches a proper value (optimal gravel proportion) does the shear strength of the SRM obtain a maximum value. At this point, a good framework is formed in the SRM. Moreover, both the fine grain soil and the coarse grain gravel can exert a maximal bearing capacity. Under the condition of a high gravel proportion and a high normal stress for the SSG, the influence of gravel size is small. The reason why it causes this change in the curves of shear stress versus horizontal displacement is that the occlusion action between the subrounded gravels is weaker than that between the breccia gravels. Thus, the gravels are easy to rearrange under high normal stress and shear stress.
For the SBG, there is a small change of the shear stress under a high gravel proportion. The main reason is that the size of the gravels has a small influence on the shear strength under a high gravel proportion.

\subsubsection{Influence of Gravel Shape on the Shear Failure} Mechanism. The gravel shape can also affect the deformation and mechanical behavior of the SRM. Taking the same gravel size of $20-30 \mathrm{~cm}$ as an example, the change of shear stress with different gravel shapes is determined by the varying gravel proportion and normal stress. As observed in the curve of shear stress versus horizontal displacement with the breccia gravel and subrounded gravel (Figure 8), the increase in the degree of shear stress under the same horizontal displacement for the SSG is greater than that for the SBG under the condition of the same gravel proportion. The shear strengths for most of the SSGs are less than those of the SBG. By comparing the SBG and the SSG, it can be observed that the smooth degree of the curve for the SSG is higher than that for the SBG, and its horizontal displacement is great when the sample reaches the yield point. The average displacement of the sample is approximately $10 \mathrm{~mm}$. For the SBG, the smooth degree of the curve is significantly lower than that for the SSG. The average displacement is approximately $15 \mathrm{~mm}$ when the sample reaches the failure state. Under the condition of the same gravel proportion, the shear stress of the SSG is less than that of the SBG when the sample is in the failure state.

Based on the curve characteristics of the shear stress versus displacement for the samples with different gravel shapes, gravel shape has a strong effect on the shear strength. The contact patterns within the gravels and the gravel and soil will be different due to the different breccia gravels. The contact pattern for the SBG is usually the "point contact". It will lead to occlusion between the different gravels in the forms of mosaic and friction. When the sample is sheared in the direct shear experiment, this combination pattern of the sample can resist the external force. The failure mode of the SBG is both gravel failure and gravel rolling. For the SSG, the contact pattern is the "face contact" between the different subrounded gravels. There is nearly no occlusion or mosaic phenomenon that emerges between the different gravels. The failure modes of the SSG are rolling and overturn, and the subrounded gravel will be nearly undamaged by the sheer force. Therefore, the shear stress and horizontal displacement of the SSG are usually less than those of the SBG.

\subsubsection{Influence of Repetitive Shear on the Shear Failure} Mechanism. Given the universality of the nature of the sample and the influence of the sample on the shear behavior, the SBG is selected to conduct the repetitive shear experiment. According to the curve of shear stress under repetitive shear experiment (Figure 9), the shear stress will decrease gradually with the increasing shear times. This indicates that the gravel damage is the main reason for the decrease in the shear stress. Under low normal stress and a low gravel proportion, the 

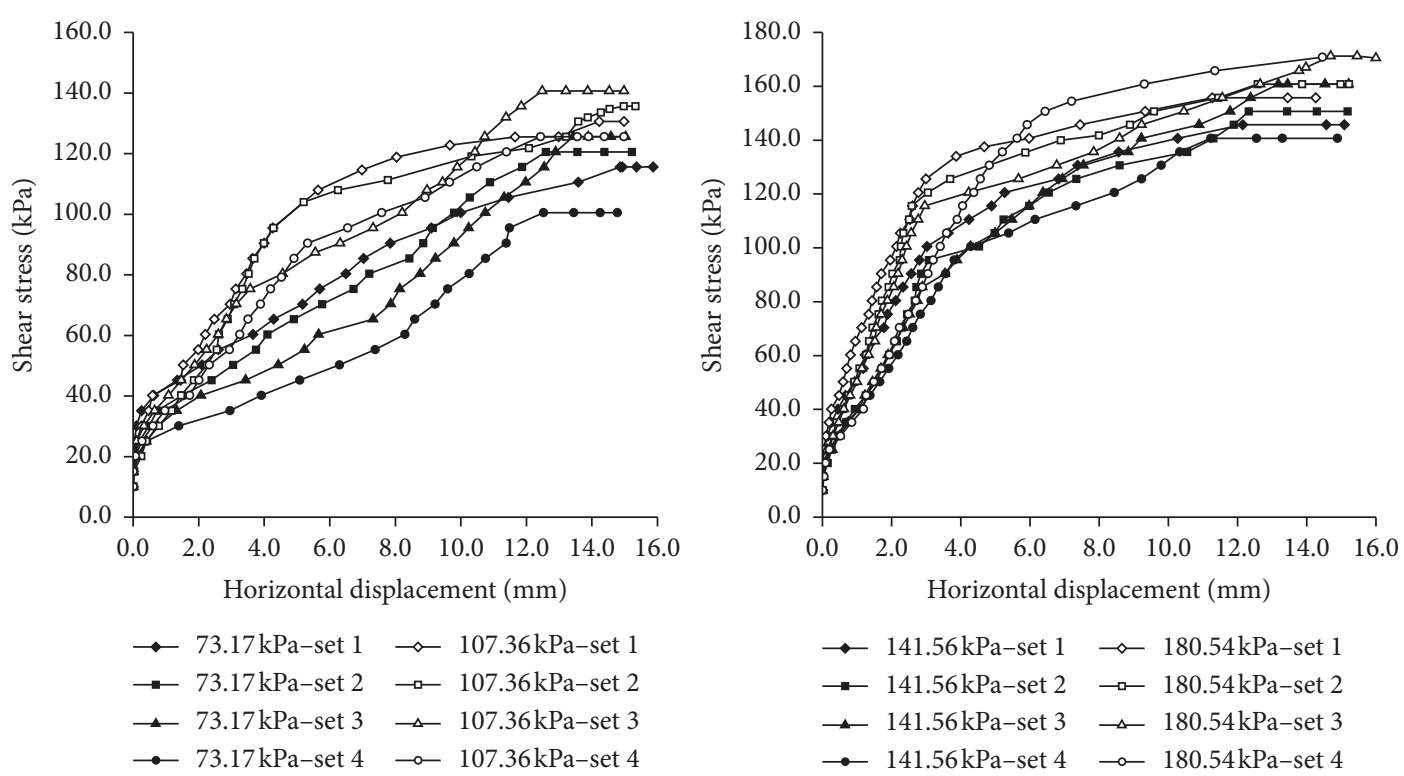

(a)
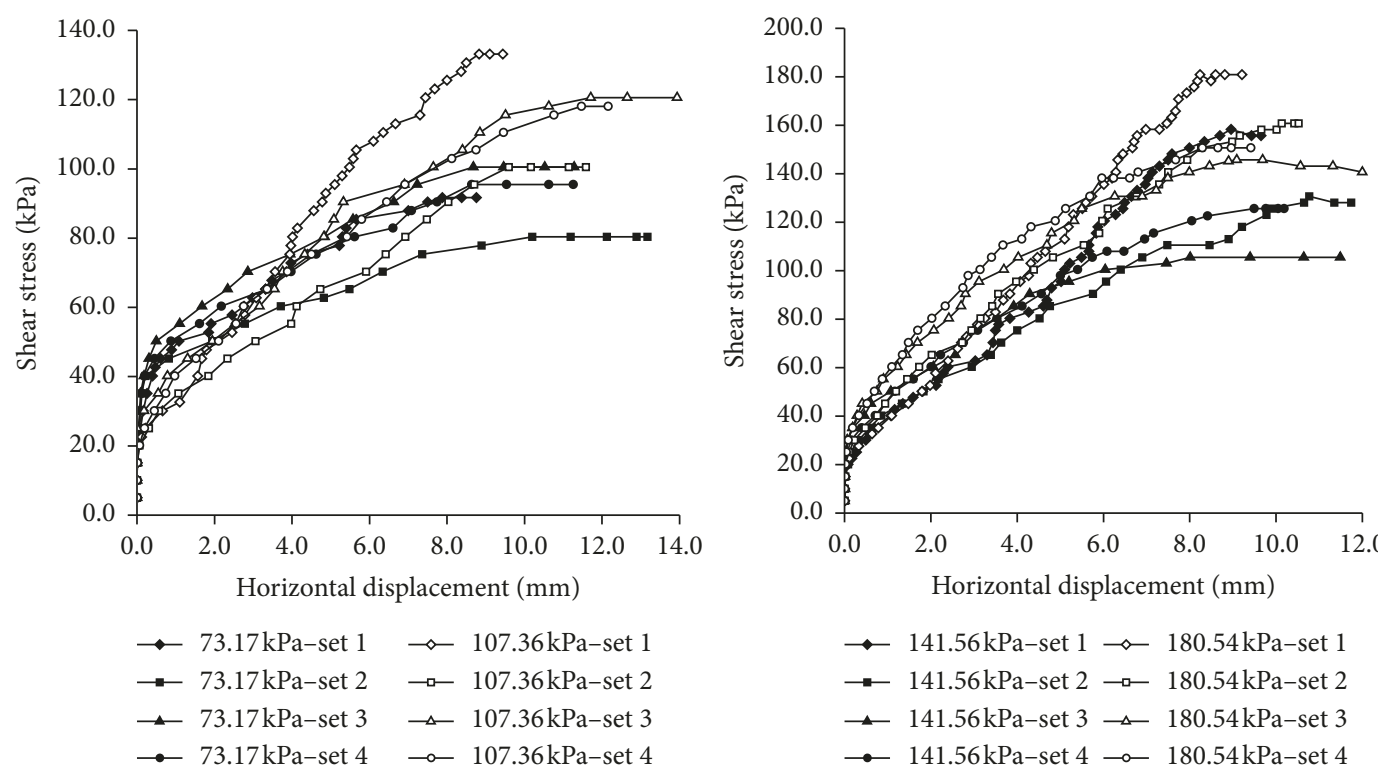

(b)

Figure 7: The curve of shear stress versus horizontal displacement with different gravel sizes. (a) SBG. (b) SSG.

"V"-shaped jumps emerge in the curve of shear stress and horizontal displacement. The frequency of this characterization will decrease with the increasing shear times. This indicates that the repetitive shear experiment will damage the breccia gravel in the SRM, which makes the shear stress versus horizontal displacement after the damage exhibit a decreasing trend. In addition, the increase of the gravel proportion can cause a substantial difference in the shear stress for the threetime shear experiments.

In the beginning of the test, the mutual compaction takes place between the different gravels under normal stress and shear stress. The sample can be maintained at the stability state by the occlusion and mosaic among the different gravels. The stress concentration appears at the contact position of the different gravels. And the cuspidal edges of the gravels are damaged under high normal stress and shear stress. The rebalance state among the gravels will be obtained by adjusting the position of the gravels. The adjusting process of the sample always emerges in the process of the shear experiment. The shear capacity of the sample will decrease with the increasing shear times and gradually trend toward the stability state. The contact patterns of the gravels change from "point contact" to the "face contact". The shape of the breccia gravel will also develop from breccias to subangular and subrounded. Correspondingly, the shear stress of the sample begins to decrease slowly. Because of the intensity of the degree of damage to the gravel, the probability gradually decreases that the "V"-shaped jumps will 

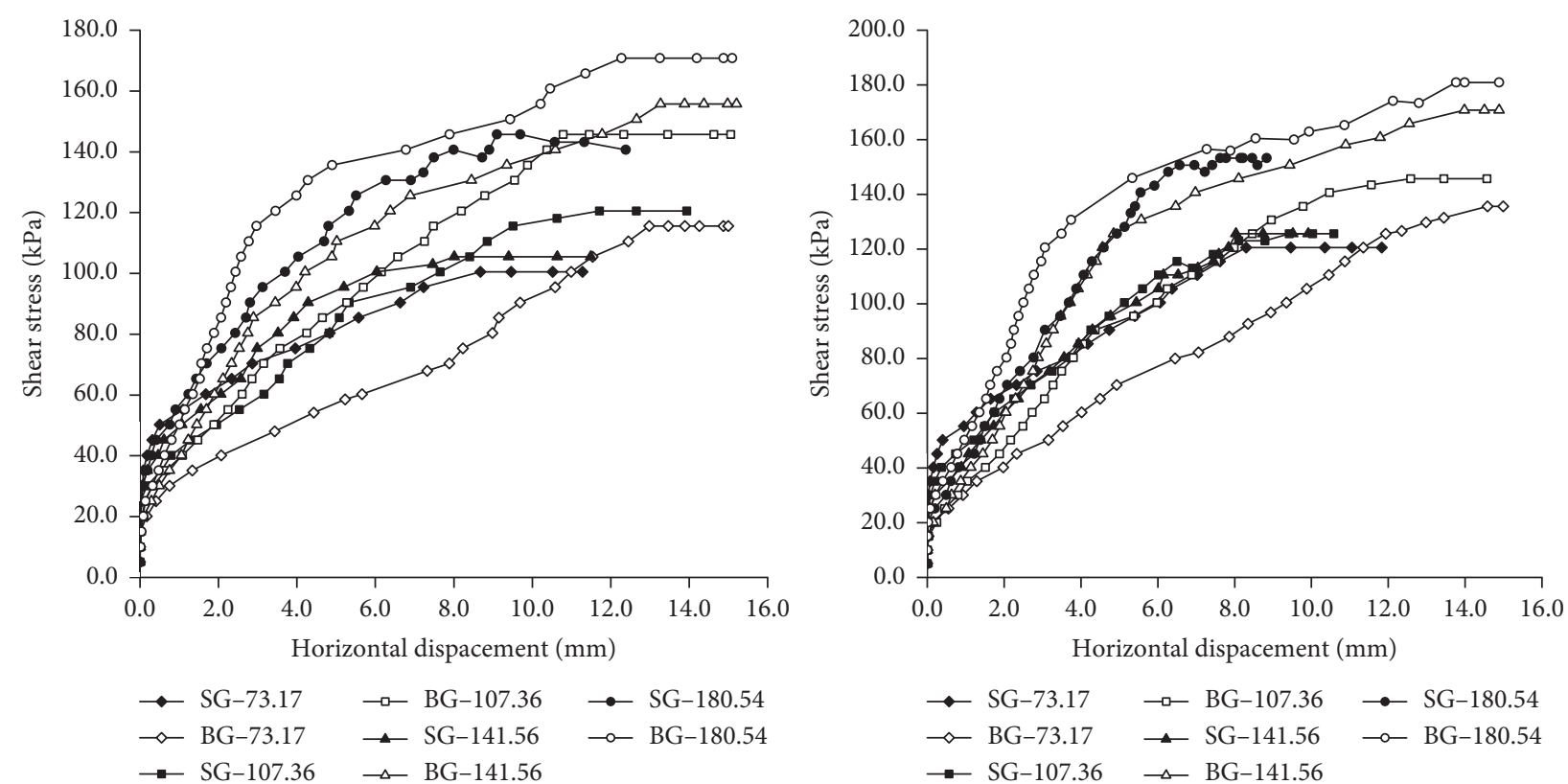

$$
\begin{aligned}
& \rightarrow \text { SG-73.17 } \rightarrow \text { BG-107.36 } \rightarrow \text { SG-180.54 } \\
& \multimap \text { BG-73.17 } \multimap \text { SG-141.56 } \multimap \text { BG-180.54 } \\
& \rightarrow \text { SG-107.36 } \rightarrow \text { BG-141.56 }
\end{aligned}
$$

(a)
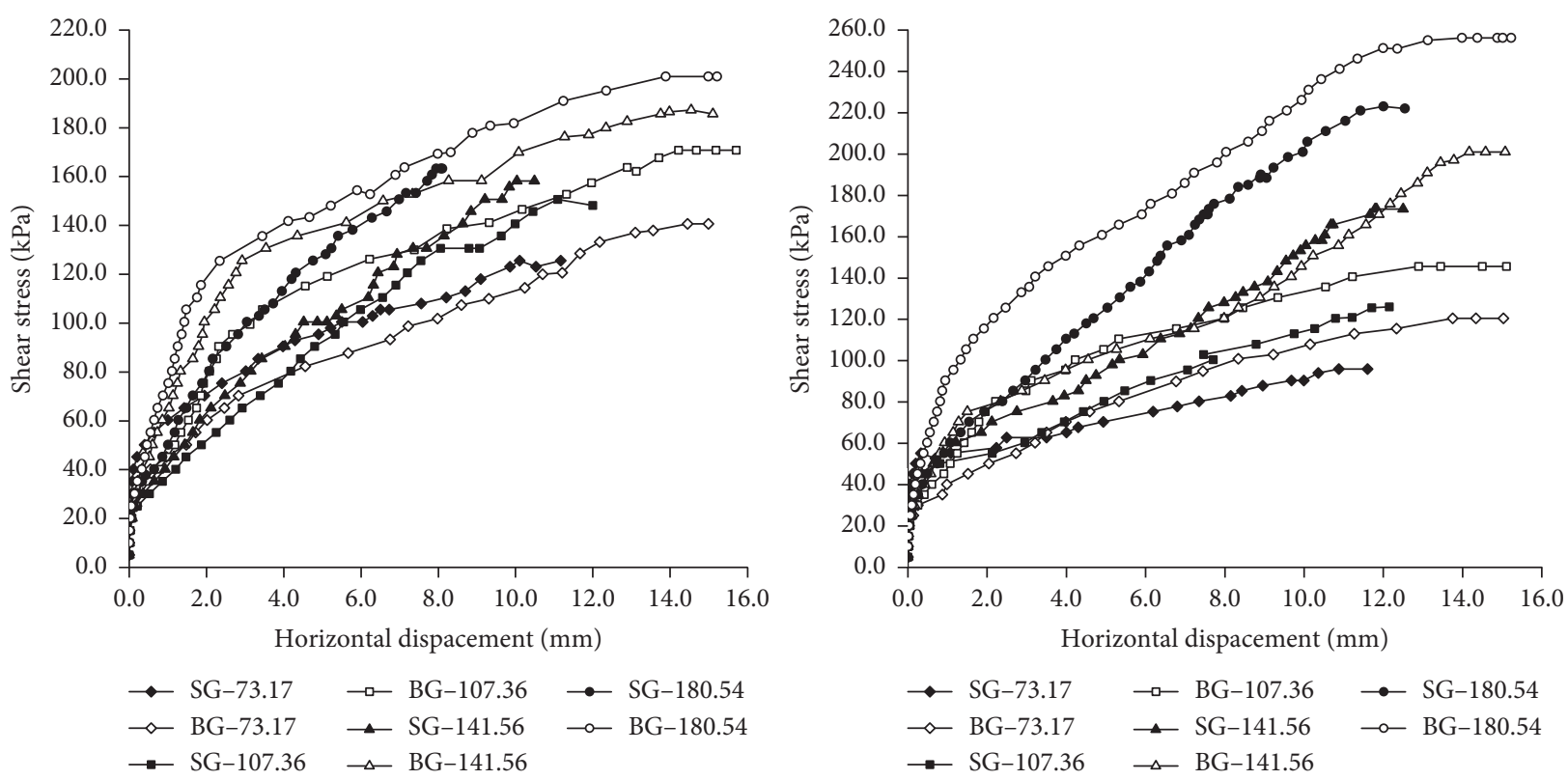

(b)

FIGURE 8: The curve of shear stress versus horizontal displacement with the breccia gravel and subrounded gravel (SG: subrounded gravel; BG: breccias gravel). (a) Gravel proportion of 10\%. (b) Gravel proportion of 30\%. (c) Gravel proportion of 50\%. (d) Gravel proportion of $70 \%$.

occur in the curve of shear stress versus horizontal displacement.

2.3. Mechanism Analysis on the Shear Failure of the SRM. After the shear experiment has been completed, the upper shear box is moved. Figure 10 illustrates the failure face of the parts of samples with set $2(10 \mathrm{~mm}-20 \mathrm{~mm})$. It includes SBG and SSG with the gravel proportion of $10 \%, 30 \%$, and $50 \%$. Figure 10 shows that the failure face of the SRM is not a plane but a complex shear zone. To a great extent, the surface morphology of the failure face depends on the gravel shape and gravel proportion at the shear plane. The breccia gravel may be damaged during the shear experiment. However, few of the subrounded gravels will be damaged. The fact that the failure face is a curve face indicates that the shear face is around the subrounded gravel and the gravels are being rearranged under the shear force.

Figure 11 shows the shear process in the SRM. Figure 11(a) displays the distribution of the gravels in the shear box. In the initial stage of the shear experiment, the sample of the SRM is densely compacted under the normal 


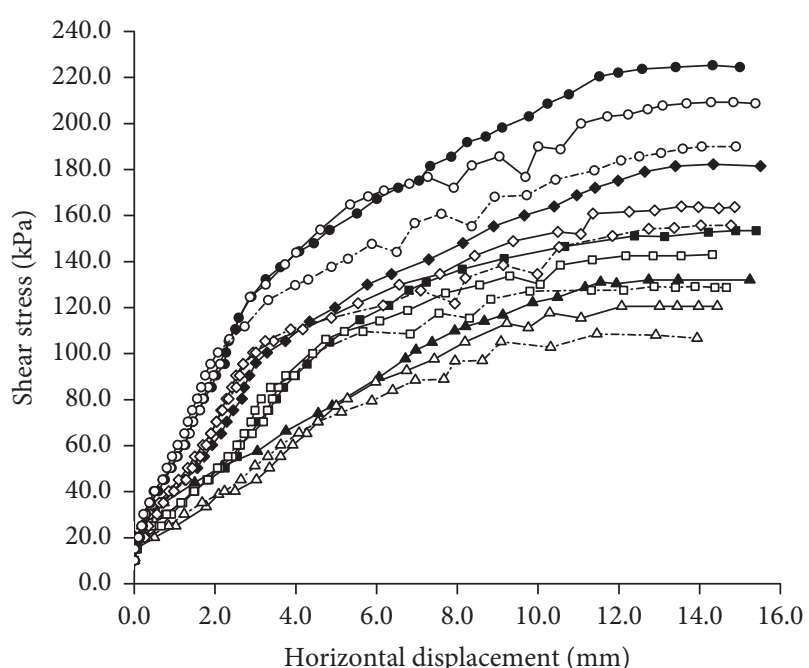

$$
\begin{aligned}
& \multimap 73.17\left(1^{\mathrm{st}}\right) \quad \rightarrow-107.36\left(2^{\mathrm{nd}}\right) \quad-\diamond \cdot 141.56\left(3^{\mathrm{rd}}\right) \\
& \rightarrow 73.17\left(2^{\text {nd }}\right) \quad-\text { - } 107.36\left(3^{\text {rd }}\right) \quad \bullet 180.54\left(1^{\text {st }}\right) \\
& \triangle 73.17\left(3^{\mathrm{rd}}\right) \multimap 141.56\left(1^{\mathrm{st}}\right) \multimap 180.54\left(2^{\text {nd }}\right) \\
& \rightarrow 107.36\left(1^{\mathrm{st}}\right) \multimap 141.56\left(2^{\mathrm{nd}}\right) \multimap-\circ \cdot 180.54\left(3^{\mathrm{rd}}\right)
\end{aligned}
$$

(a)

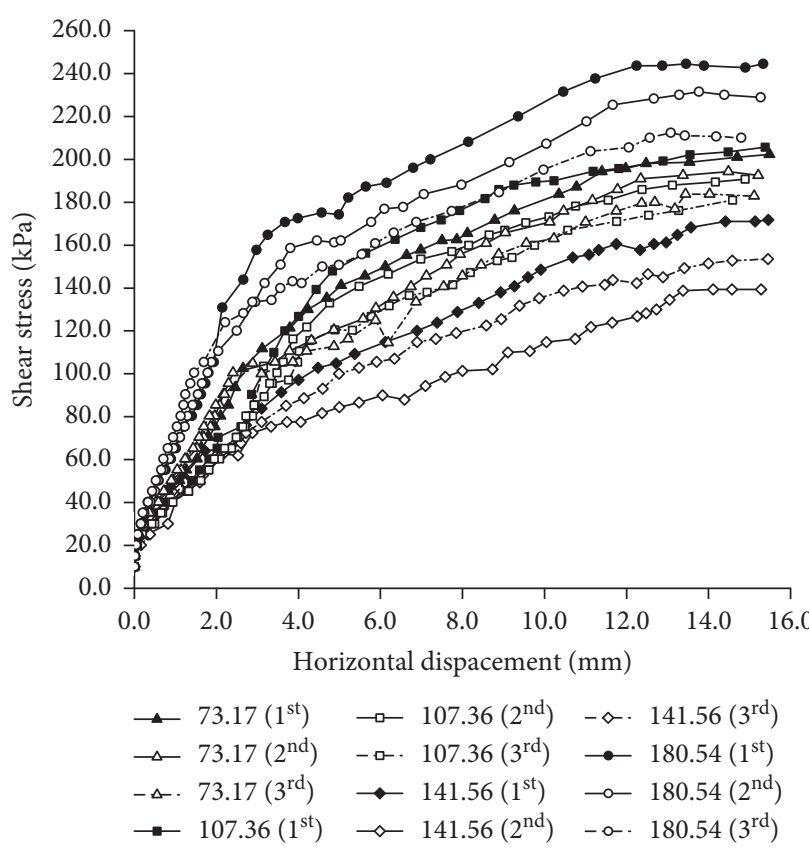

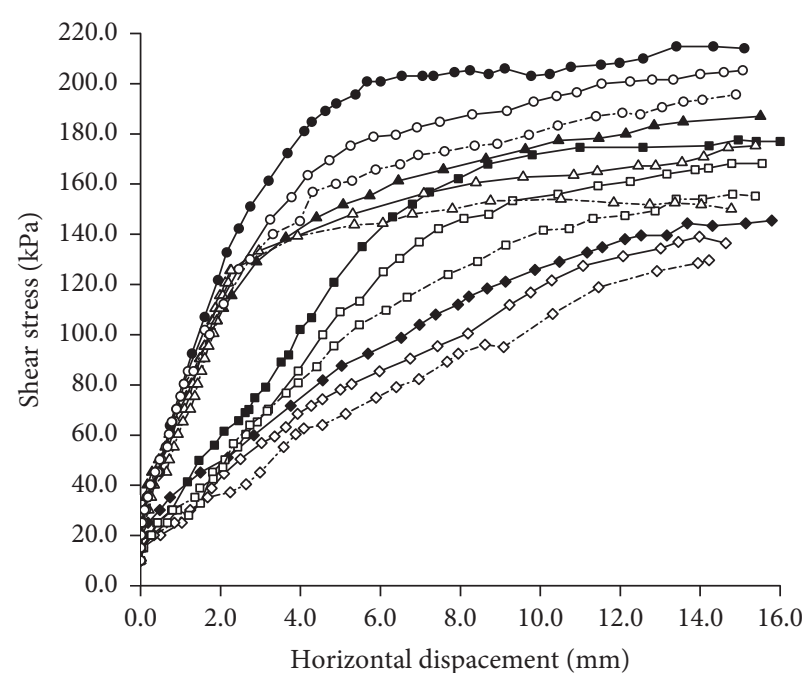

$$
\begin{aligned}
& \rightarrow 73.17\left(1^{\mathrm{st}}\right) \quad \longrightarrow-107.36\left(2^{\text {nd }}\right)-\triangle 141.56\left(3^{\text {rd }}\right) \\
& \multimap 73.17\left(2^{\text {nd }}\right)-\text { - }-107.36\left(3^{\text {rd }}\right) \multimap 180.54\left(1^{\text {st }}\right) \\
& -\diamond .73 .17\left(3^{\mathrm{rd}}\right) \multimap 141.56\left(1^{\mathrm{st}}\right) \multimap 180.54\left(2^{\mathrm{nd}}\right) \\
& \rightarrow 107.36\left(1^{\text {st }}\right)-\triangle 141.56\left(2^{\text {nd }}\right)-0.180 .54\left(3^{\text {rd }}\right)
\end{aligned}
$$

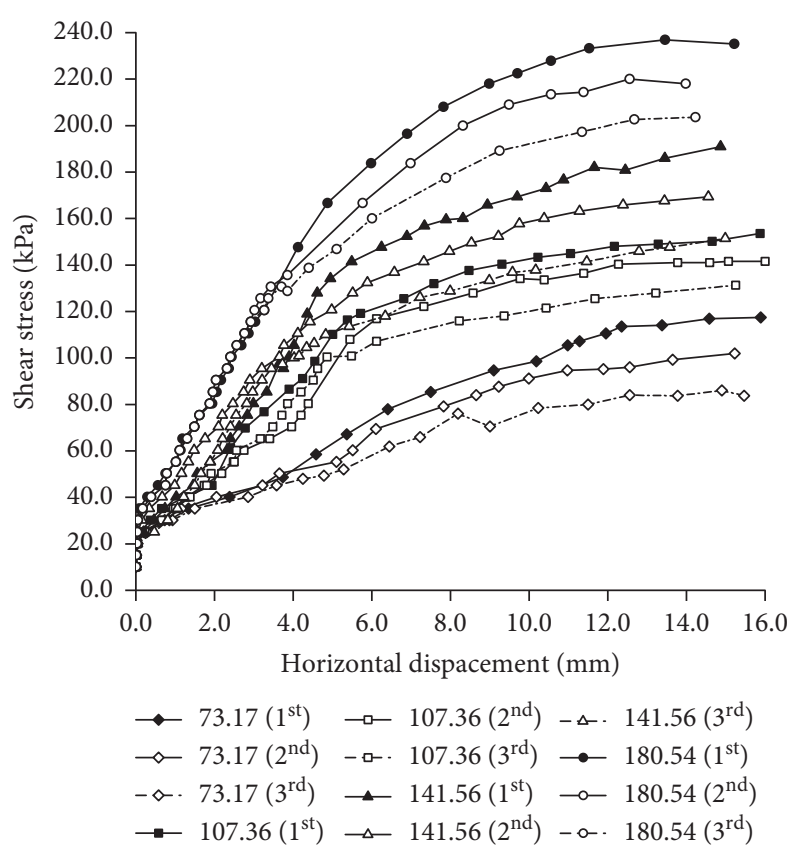

(b)

FIGURE 9: The curve of shear stress under repetitive shear experiment. (a) Gravel proportion of 10\%. (b) Gravel proportion of 30\%. (c) Gravel proportion of $50 \%$. (d) Gravel proportion of $70 \%$.

stress and small shear force. The mutual contact and occlusion among the grains appear in the SRM. With the development of the shear process, the shear stress increases gradually. The gravels in the SRM begin to roll and rearrange. This stage is the linear stage for the curve of shear stress versus horizontal displacement (Figure 11(b)). The "V"-shaped jumps in the curve will occur in the process of the shear experiment. The main reason is that the small gravels fill the pores of the gravels, and the big gravel is damaged. The sample is damaged in the form of plastic failure. In terms of the hard gravel, the small grains will turn around it, causing the shear failure to be not a plane but an uneven face or shear zone (Figure 11(c)).

For the SRM with the same gravel sizes, the contact probability among the gravels increases with increasing gravel proportion. Figure 12 shows the contact types under the different gravel proportions and gravel sizes. Based on Figure 12(a), the gravels in the SRM are in a state of suspension under the lower gravel proportion, so its shear strength is afforded primarily with soil. When the gravel 

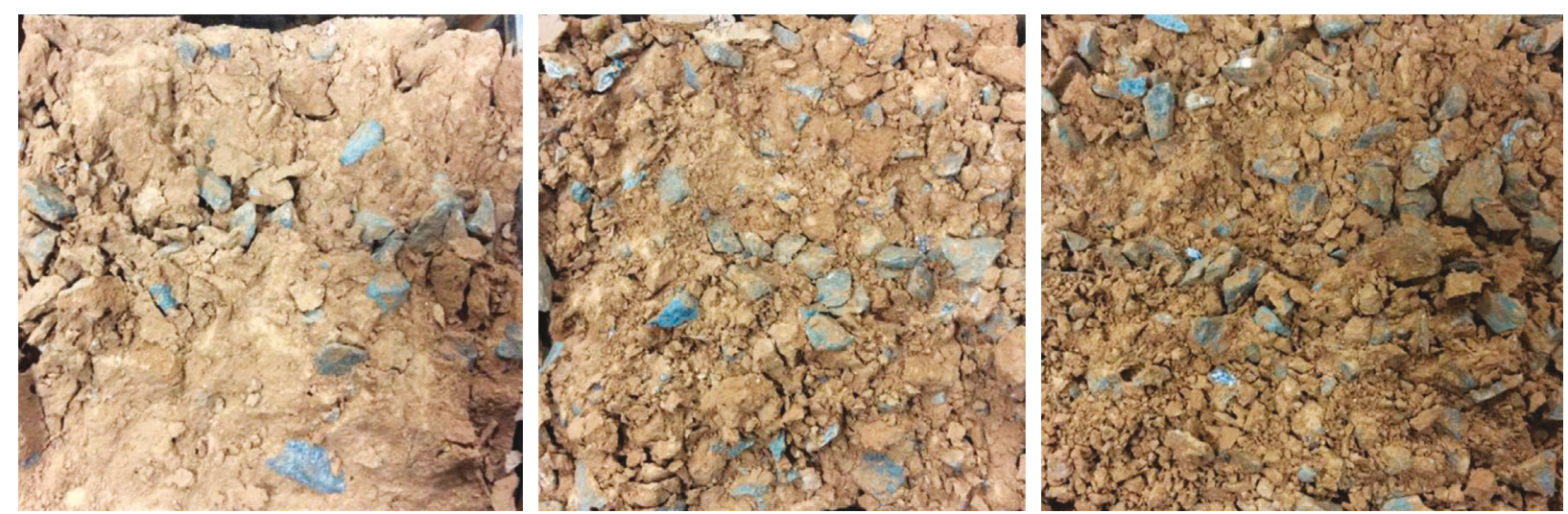

(a)
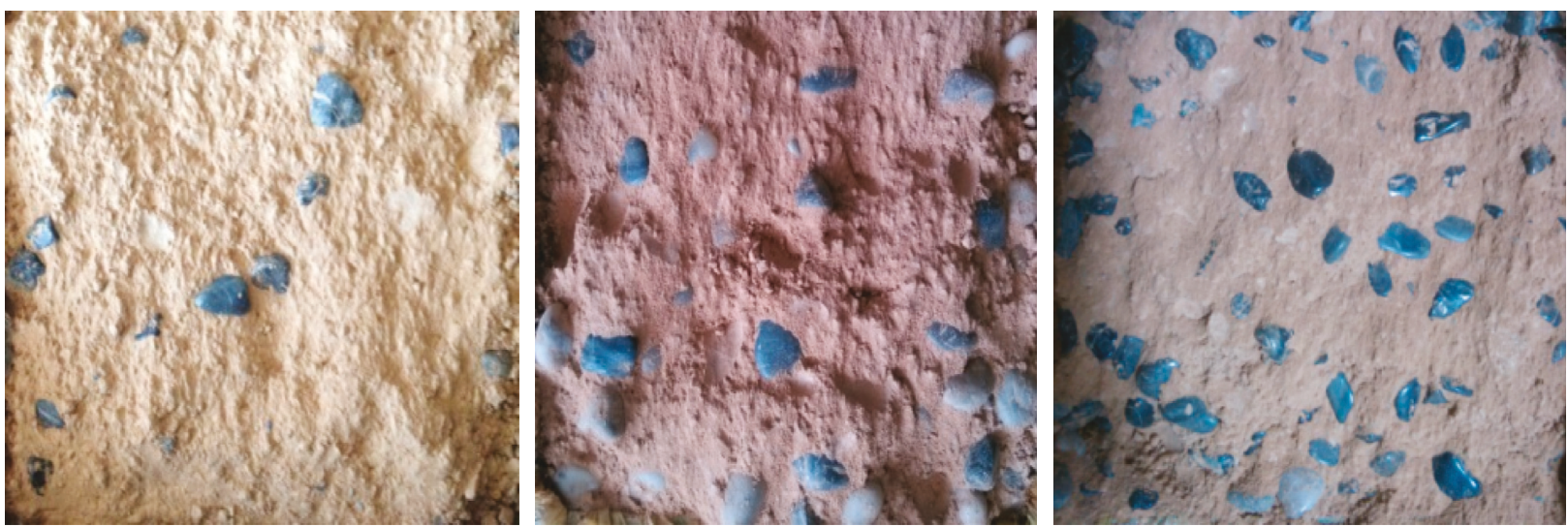

(b)

FIGURE 10: Failure face for the parts of samples. (a) SBG. A: gravel proportion of 10\%. B: gravel proportion of 30\%. C: gravel proportion of $50 \%$. (b) SSG. A: gravel proportion of $10 \%$. B: gravel proportion of $30 \%$. C: gravel proportion of $50 \%$.

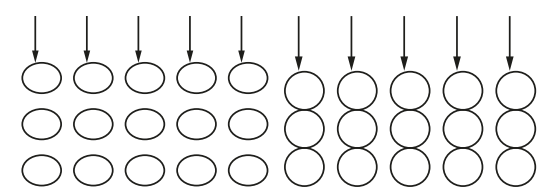

(a)

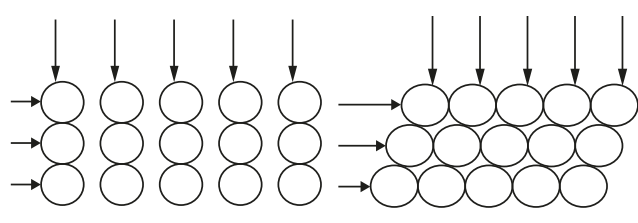

(b)

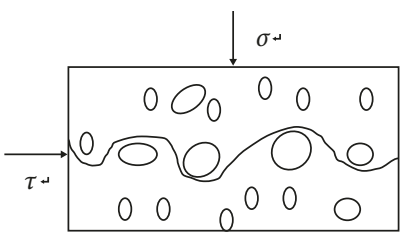

(c)

FIGURE 11: Shear process in the SRM. (a) Pressure dense phase. (b) Shear phase. (c) Shear face (zone).

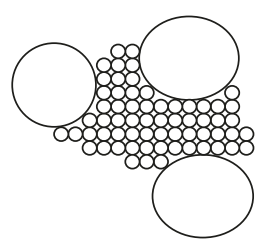

Lower

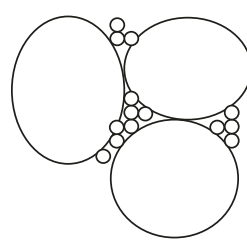

Middle

(a)

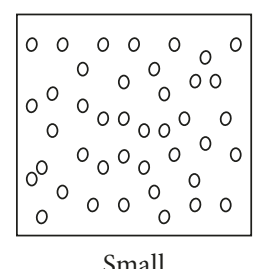

High

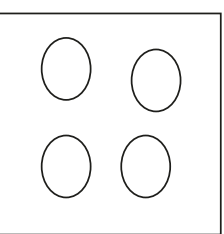

Big

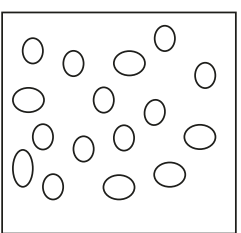

Moderate

(b)

FIGURE 12: Contact types under the different gravel proportions and gravel sizes. (a) Gravel proportion. (b) Gravel size. 
proportion reaches a certain degree, i.e., the optimal gravel proportion, parts of the gravel begin to contact each other, and the soil grains are appropriately sized to fill the gravel pores. The shear strength is to a large extent afforded by the soil and gravels under the present circumstances, which can make the soil and gravel fully exert their bearing capacities. However, it is not the high gravel proportion that can lead to the high shear strength for the SRM. When the gravel proportion reaches a high degree, the shear strength of the SRM will nearly be formed by friction and occlusion in the gravel. The soil grains cannot fully fill the pores formed by the gravel, which results in the failure to exert the bearing capacity of the soil. Thus, the shear strength of the SRM will decrease gradually. Therefore, the proper gravel proportion is a crucial index to improve the shear strength of the SRM.

As far as the same gravel proportion is concerned, the opposite relationship exists between the size and number of gravels. That is to say, the small gravel size and the large gravel size have little impact on the shear strength. Small grain size does not adequately form the framework among the gravels due to its small gravel size, and the large grain size does not adequately form the framework due to its minimal quantities (Figure 12(b)). Occasionally, it can be observed that a great value for the aforementioned circumstance can be obtained. This indicates that the shear strength of the SRM depends to a great extent on the amount of the gravel at the shear zone. Therefore, the proper gravel size for the same gravel proportion is very important to shear strength of the SRM.

Figure 13 shows the contact types among the gravels with different shapes. As known, the shear strength is constituted with friction and occlusion among the coarse grains and the cohesion between the coarse grain and fine grain. The grains at the shear zone will roll and move under the shear force in the process of the shear experiment. Therefore, the sheared sample will exhibit volumetric strain. Due to the poor specificity and the degree of sphericity of the SBG, the gravels in the SRM will make contact in the form of a "point contact," which can easily damage the angular gravel (Figure 13(a)). For the SSG, the contact type among the subrounded gravel is the "face contact," which cannot form occlusion among the different gravels. In summary, the shear strength of the SBG is greater than that of the SSG. The shear strength of SBG will decrease gradually with the increasing shear times because the angular gravel will be damaged in the repetitive shear experiment.

\section{Identification of Strength Parameters}

The aforementioned works primarily focus on failure mechanism by considering certain influencing factors, such as the gravel proportion, gravel size, gravel shape, and the results of the repetitive shear experiment. According to the analytical results of the shear stress and horizontal displacement, shear strength parameters are not a simple superposition of that of the soil and gravel. Research on the shear strength parameters of SRM is necessary to evaluate

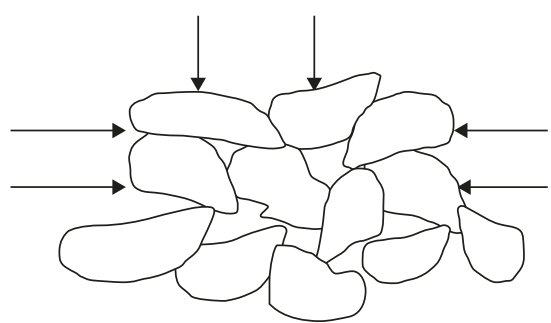

(a)

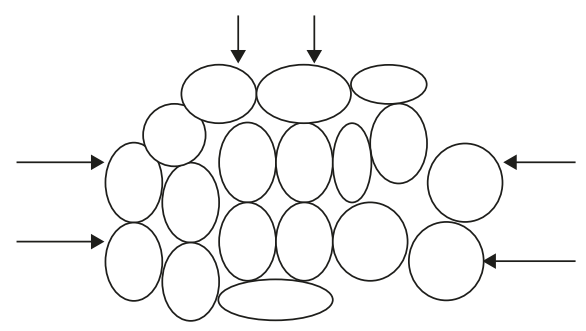

(b)

FIGURE 13: Contact types among the gravels with different shapes. (a) SBG. (b) SSG.

the stability of the relevant project using the SRM as an engineering material.

3.1. Influence of the Gravel Proportion on Shear Strength. Figure 14 exhibits the relationship between the cohesion of the SRM and the gravel proportion for the different sets of samples. To research the influence of the gravel proportion on the cohesion of the SRM, four sets of samples with the breccia gravel and the subrounded gravel are selected to analyze these change laws with the shear times.

According to Figure 14, it can be observed that the cohesion of the SBG increases with the increasing gravel proportion when the gravel proportion is less than $50 \%$. The increasing rate of the cohesion gradually becomes large with the increased shear times. However, the cohesion of the SBG decreases markedly with gravel proportion increasing when the gravel proportion is more than $50 \%$. Although the value of the cohesion decreases with the increased shear times, the decreasing rate is clearly strengthened when the shear times increase. In addition, the discrete degree of the cohesion decreases with the shear times increasing for the different gravel proportions. Therefore, this phenomenon can be found from the repetitive shear experiment which will create breccia gravel damage, which is a primary reason for the rate change of the SBG. Similar changes of the cohesion with the gravel proportion for the SBG emerge for the SSG. As seen in Figure 14(d), the cohesion undergoes significant changes in value compared to that of the SBG.

Figure 15 displays the relationship of the internal friction angles of SRM and gravel proportion. Based on Figure 15, the internal friction angles present a decreasing trend with increasing gravel proportion for the SBG when the gravel proportion is $<30 \%$. At the same time, the internal friction angle presents an increasing trend when 


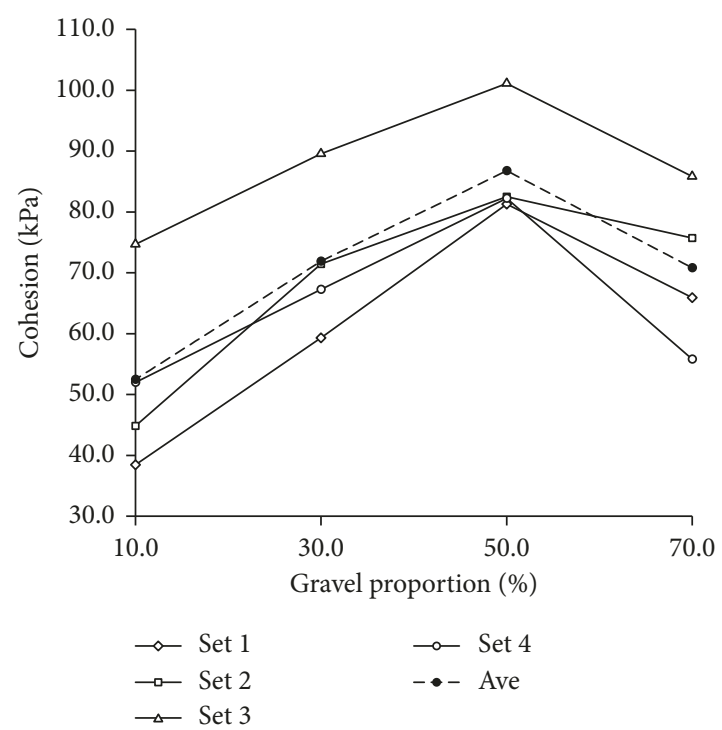

(a)

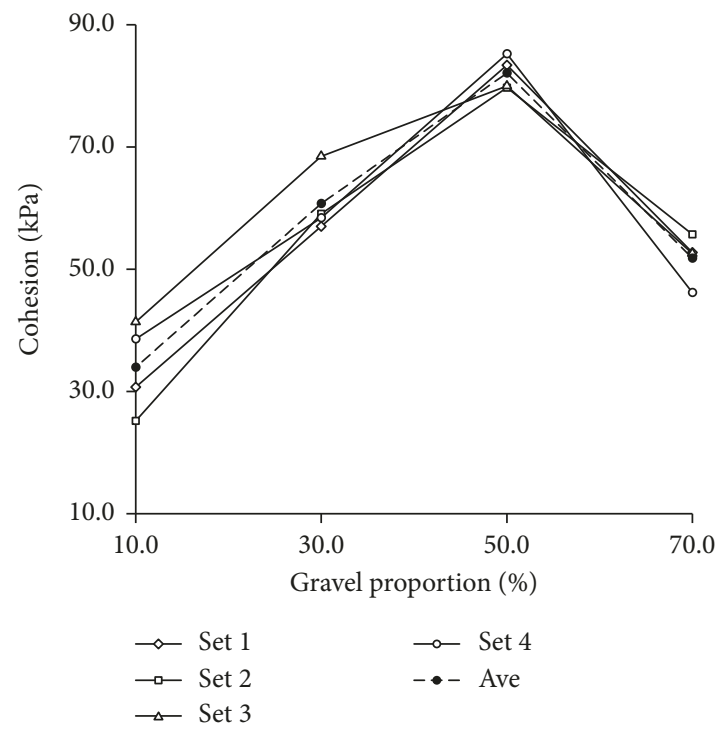

(c)

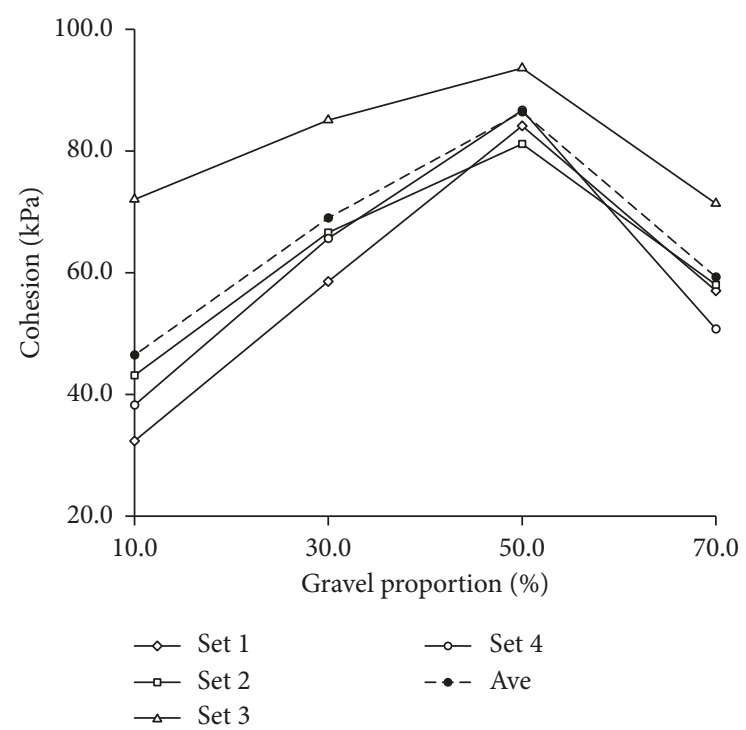

(b)

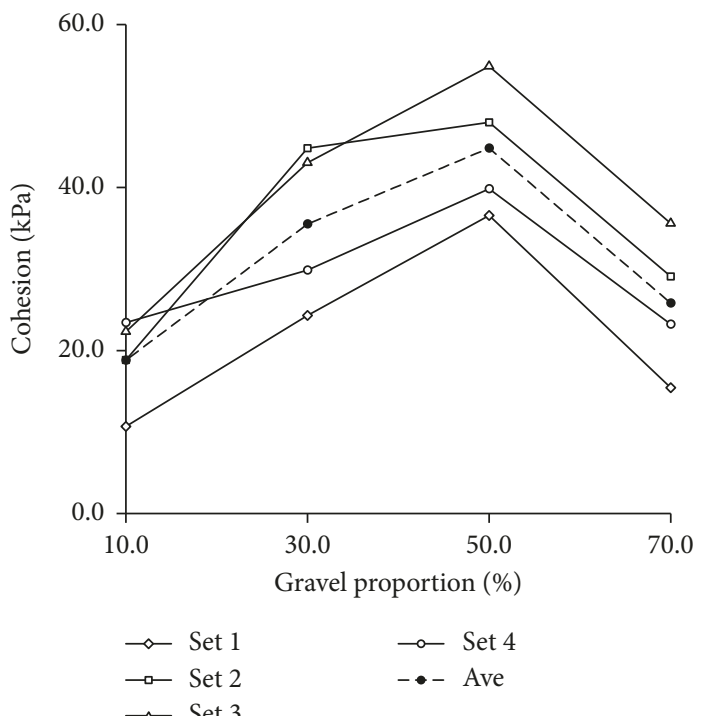

(d)

FIGURE 14: Cohesion of the SRM samples with the different sets. (a) SBG for the 1st shear. (b) SBG for the 2nd shear. (c) SBG for the 3rd shear. (d) SSG.

the gravel proportion is $>30 \%$. The internal friction angle exhibits a decreasing trend with increasing shear times. The discrete degree of the internal friction angle will gradually become large with the shear times being increased. This indicates that the repetitive shear process creates the gravel damage. The gravel size will trend towards uniformity, which makes the SRM a poor particle grade. This is completely different compared to the initial state of the sample. For the SSG, the change laws are different than those of the SBG. The clear increase of the internal friction angle emerges at gravel proportions of less than $50 \%$ and then it exhibits a decreasing trend. This indicates that the effect of SSG on the internal friction angle is small because there is little damage to the subrounded gravel.
As is well known, the SRM is an anisotropic and nonhomogeneous geological material; thus, it may present unusual change law for the shear parameters. To research the gravel proportion affecting on the shear strength, the Mohr-Coulomb criterion is selected to calculate the shear strength with the normal stress of $70 \mathrm{kPa}$. Figure 16 presents the shear strength results affected by the gravel proportion for the SBG and SSG. According to Figure 16, the change law of the shear strength for the SRG increases first and then decreases. The demarcation point regarding the gravel proportion is $50 \%$. The change degree of the shear strength with the gravel proportion for the SSG is less than that for the SBG. An analysis of the change law of the shear strength with the gravel proportion demonstrates the clear influence of the gravel proportion on the shear 


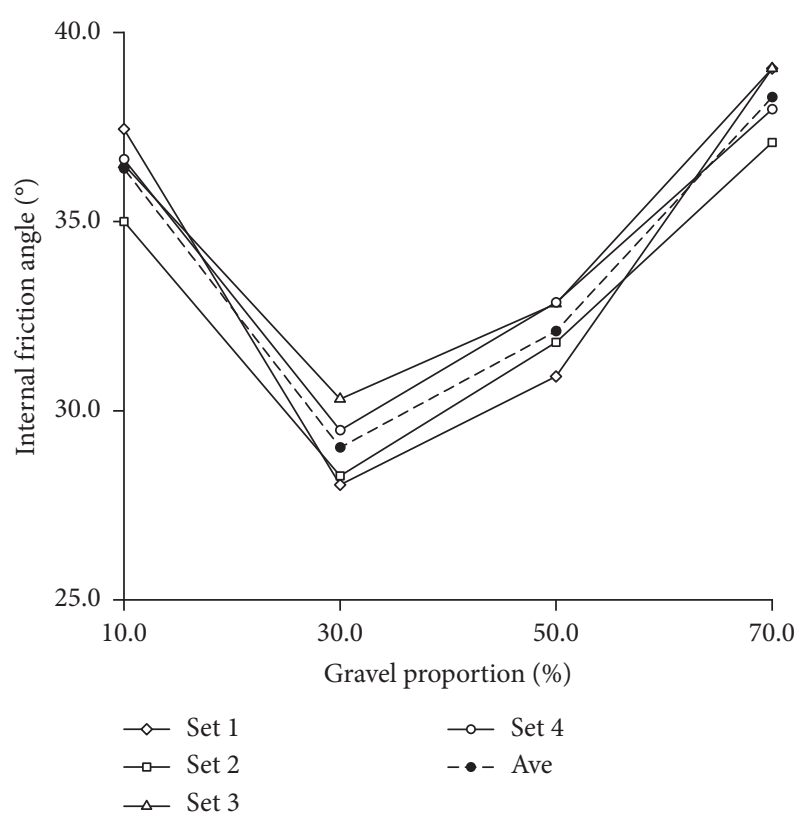

(a)

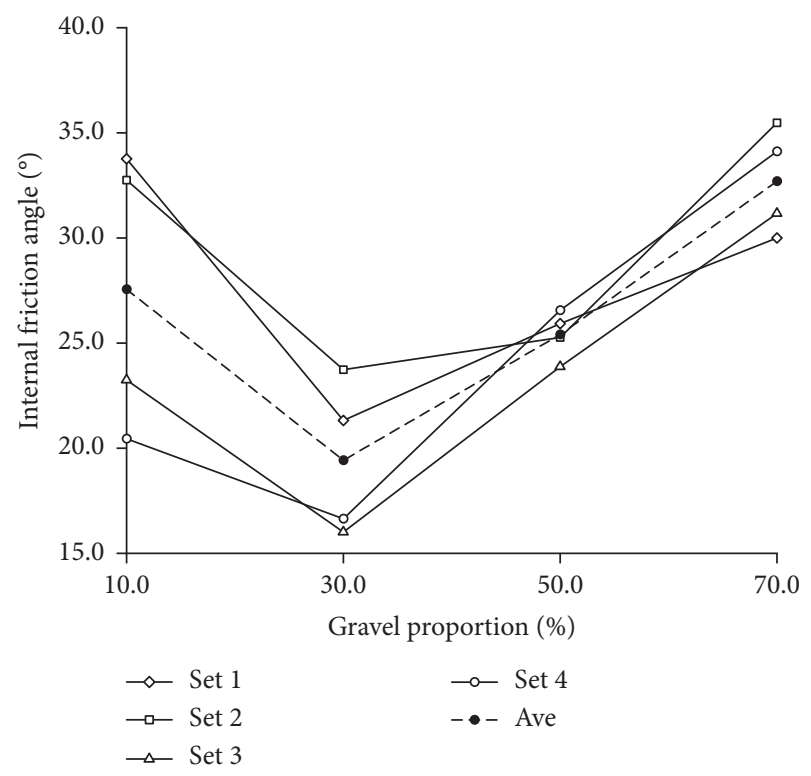

(c)

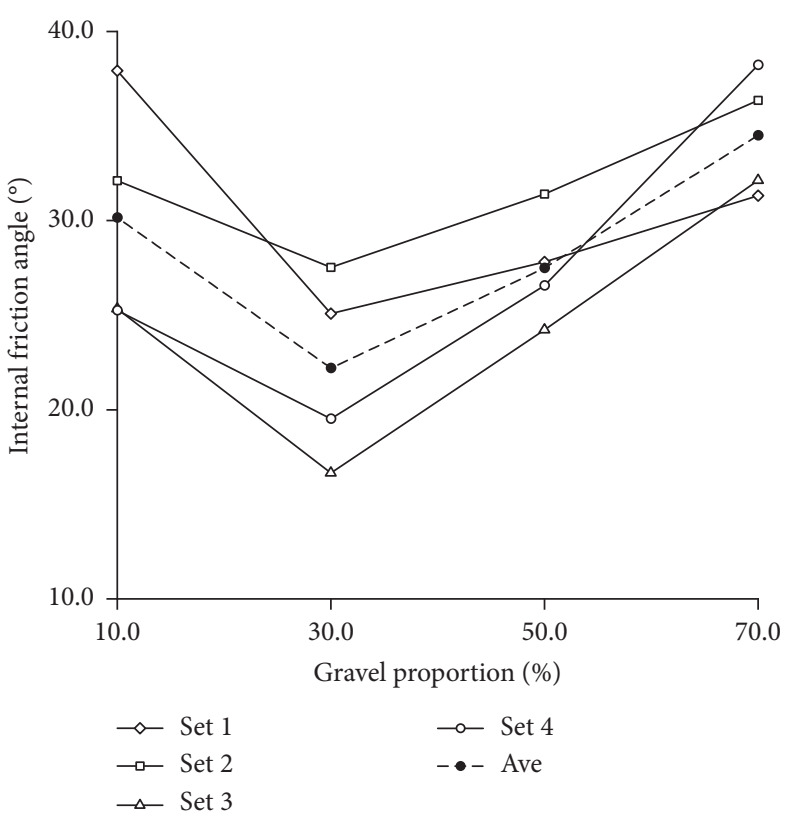

(b)

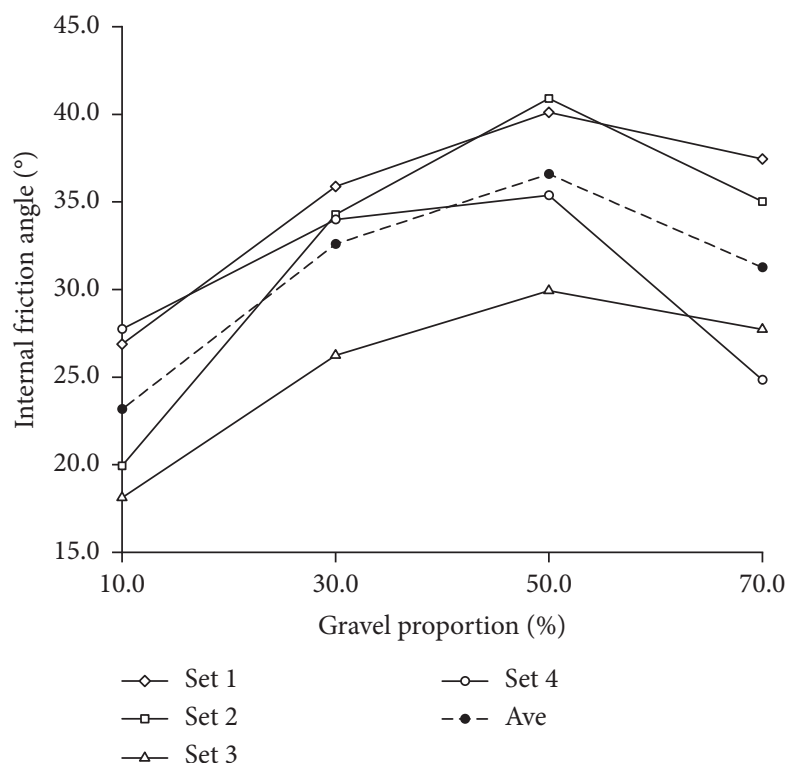

(d)

FIGURE 15: Internal friction angles of the SRM samples. (a) SBG for the 1st shear. (b) SBG for the 2nd shear. (c) SBG for the 3rd shear. (d) SSG.

strength. The influence of the gravel proportion is stronger on cohesion than the internal friction angle. As a whole, the shear strength of SRM increases with the gravel proportion increasing when the gravel proportion is less than $50 \%$. The shear time makes the change rate of the shear strength increase markedly when the gravel proportion is less than $50 \%$ and decrease markedly when the gravel proportion is more than $50 \%$. Therefore, a high gravel proportion does not enhance the shear strength of the SRM but in fact decreases the shear strength. The optimal gravel proportion of the SRM is approximately $50 \%$ based on the aforementioned analysis.
3.2. Influence of Gravel Size on Shear Strength. Gravel size is another important influencing factor for the shear strength of SRM. Figure 17 displays relationship between the cohesion and gravel size for the SBG and the SSG.

For the SBG with the first and the second shear experiment, the change laws of the curves between the cohesion and gravel size are similar. The cohesion with the different gravel proportions presents an increase first and then decreases with the gravel size increasing. The gravel size causing this change is $20.0-30.0 \mathrm{~mm}$. When the gravel proportion reaches $70 \%$, the cohesion with the gravel size of $5.0-10.0 \mathrm{~mm}$ begins to increase markedly and then 


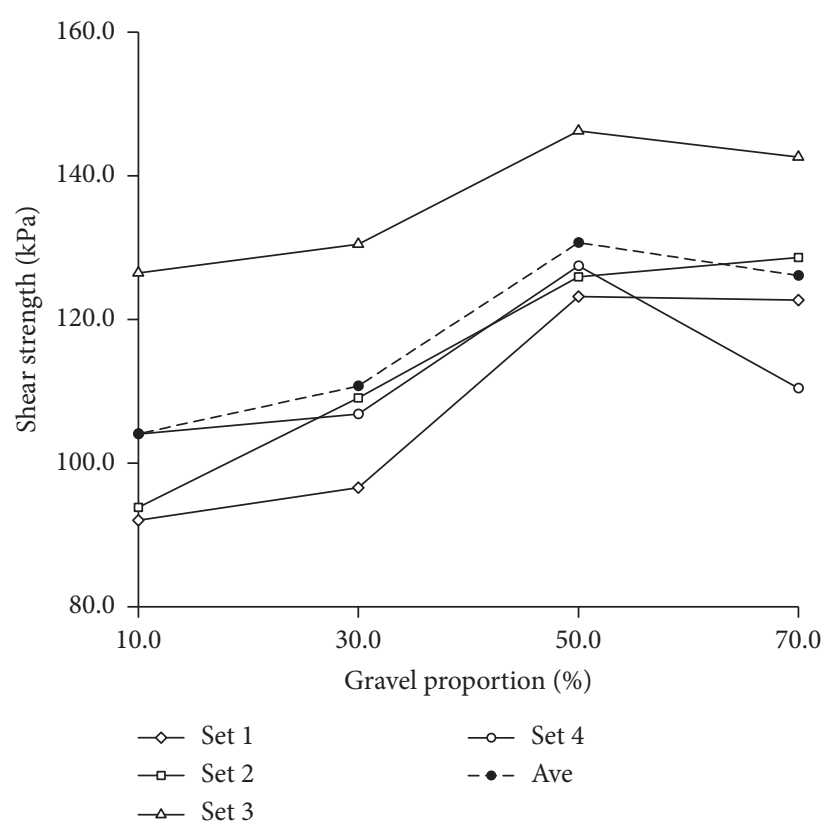

(a)

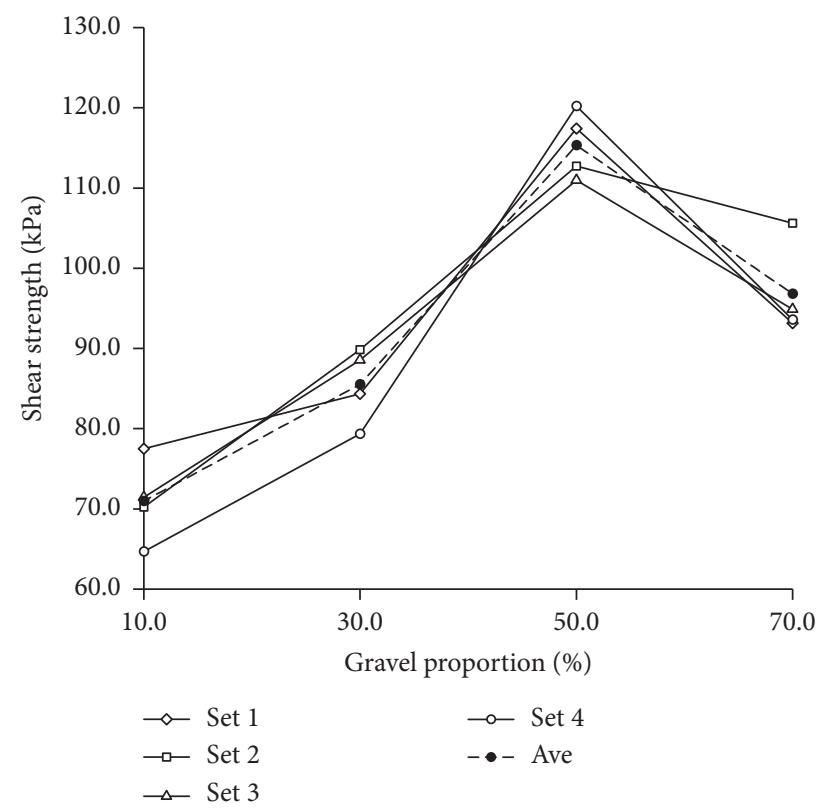

(c)

FIGURE 16: Shear strengths of the SRM samples with different sets. (a) SBG for the 1st shear. (b) SBG for the 2nd shear. (c) SBG for the 3rd shear. (d) SSG.

decreases. The same change law does not appear in the $3 \mathrm{rd}$ shear experiment. According to Figure 17(c), the cohesion has a small change, with the gravel size increasing during the process of the third shear experiment. This indicates that the shear behavior causes the size of grains to trend to uniformity. As a whole, the change trend of cohesion and gravel size first increases and then begins to decrease. There is nearly no law for cohesion with gravel size in the process of the 3rd shear experiment. This demonstrates that the cohesion of the SBG will trend toward uniformity with the increased shear times. With respect to the SBG, there is a

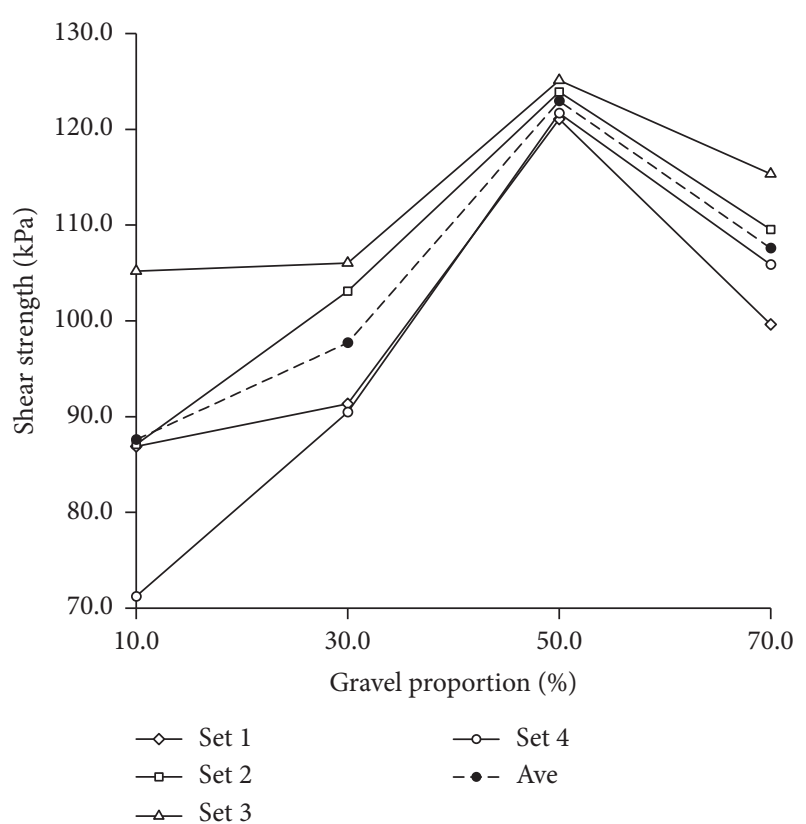

(b)

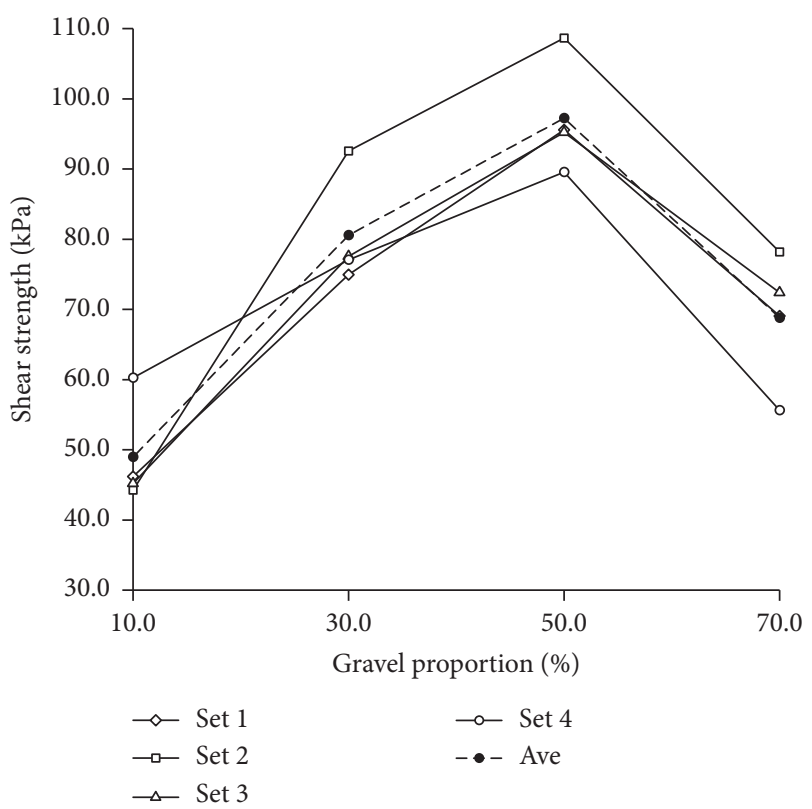

(d) small change for the cohesion when the gravel size is less than $20 \mathrm{~mm}$. For the SSG, the relationship between the cohesion and gravel size increases first and then decreases, especially for the sample with the gravel proportion of $50 \%$. In addition, the change ratio of the cohesion for the SSG is greater than that of the SBG. The cohesion in value for the SSG is greater than that for the SBG under the same gravel size and gravel proportion.

Figure 18 presents the internal friction angle changed with the gravel size. For the SBG, the internal friction angle of the first shear experiment has a small change when the 


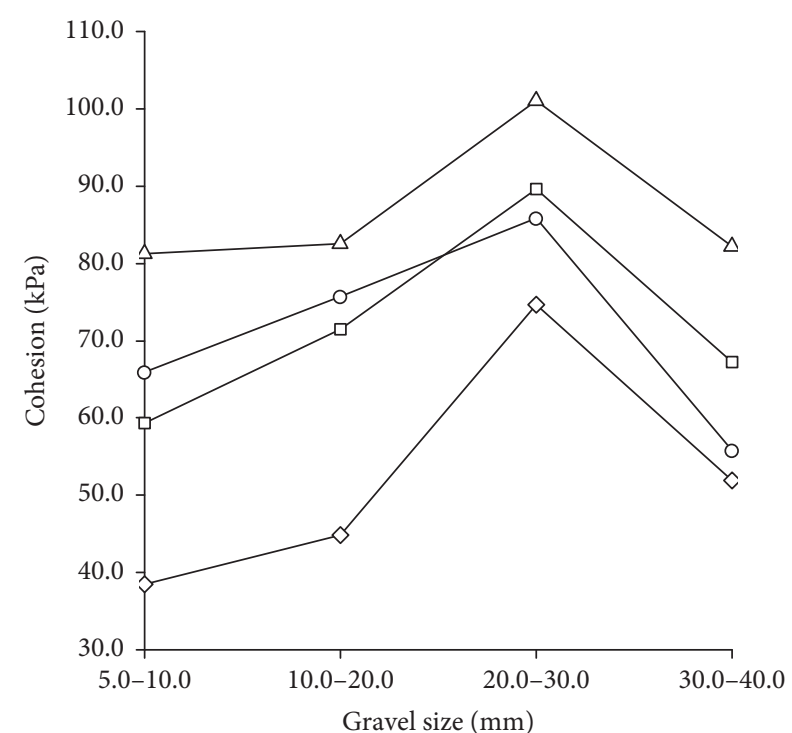

$\prec 10 \%$

$\rightarrow-30 \%$

$\triangle-50 \%$

(a)

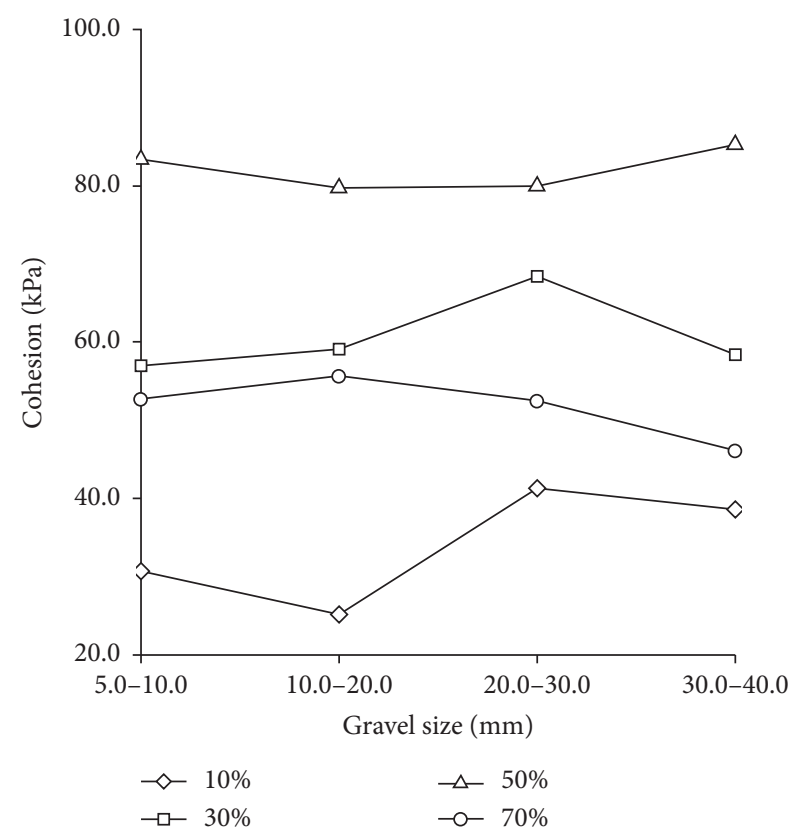

(c)

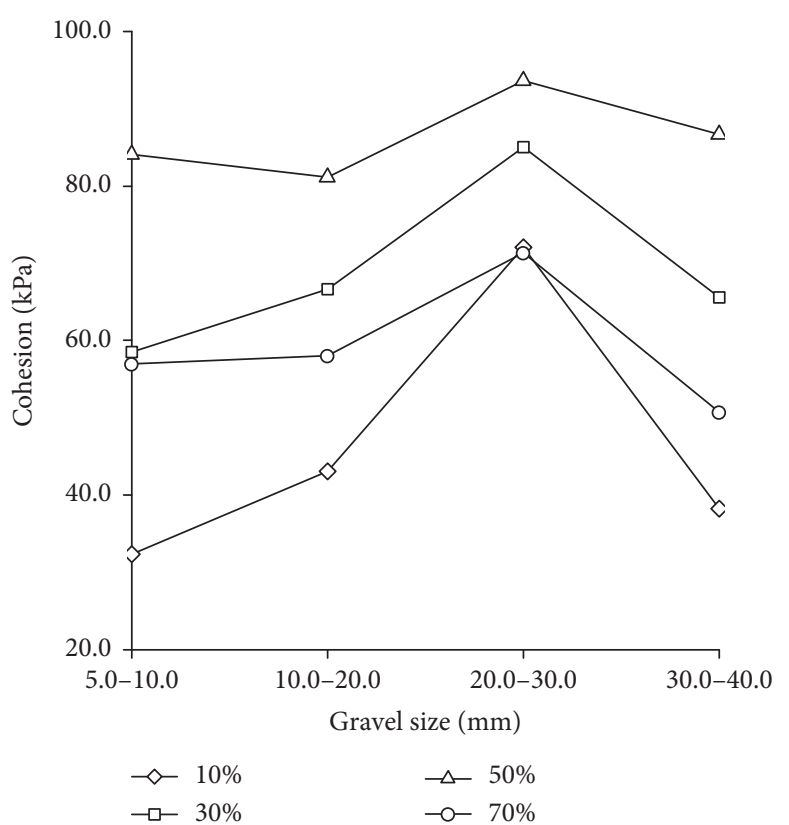

(b)

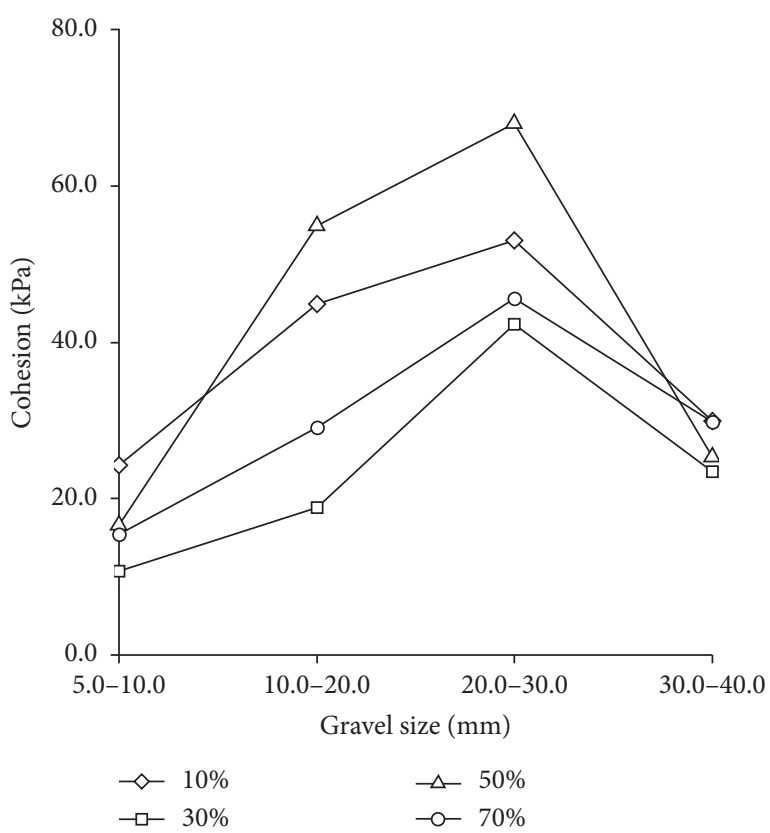

(d)

FIGURE 17: Cohesions of the SRM samples with different contents of gravel. (a) SBG for the 1st shear. (b) SBG for the 2nd shear. (c) SBG for the 3rd shear. (d) SSG.

gravel size is less than $30 \mathrm{~mm}$. However, internal friction angle will differ with increasing shear times. With respect to the second and third shear times, when the gravel size is less than $10-20 \mathrm{~mm}$, the internal friction angle will increase for the gravel proportions of $30 \%$ and $70 \%$. When the gravel size is between $10-20 \mathrm{~mm}$ and $20-30 \mathrm{~mm}$, the internal friction angle will decrease with gravel size. Then, the internal friction angle will increase with the gravel size, except for the cases of the gravel proportion being $10 \%$. It also will decrease gradually with shear times being increased. However, the decreasing ratio is less than that of the cohesion. For the SSG, when the gravel size is less than $20-30 \mathrm{~mm}$, the internal friction angle will decrease for the different gravel proportions. Subsequently, an increasing trend will appear when the gravel size increases. As a whole, the value in the internal friction angle of SSG is less than the one of SBG.

To study the entire influence of the gravel size on shear strength, the Mohr-Coulomb criterion with the normal stress of $70 \mathrm{kPa}$ is selected to study shear strength. Figure 19 


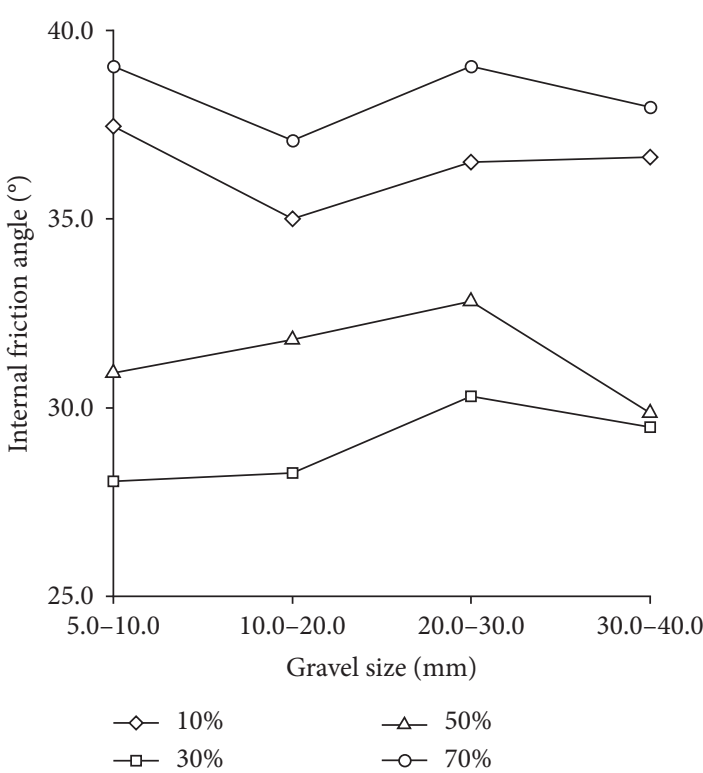

(a)

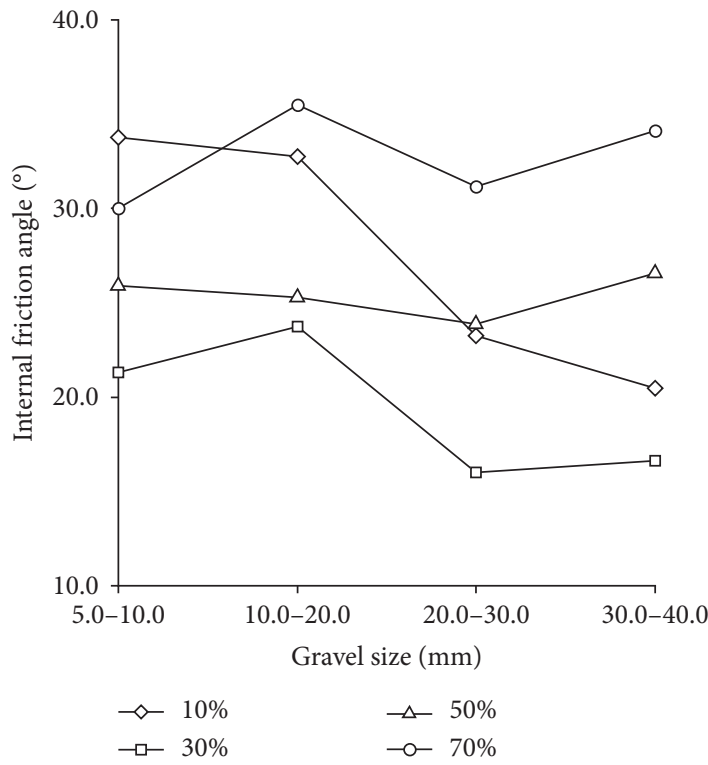

(c)

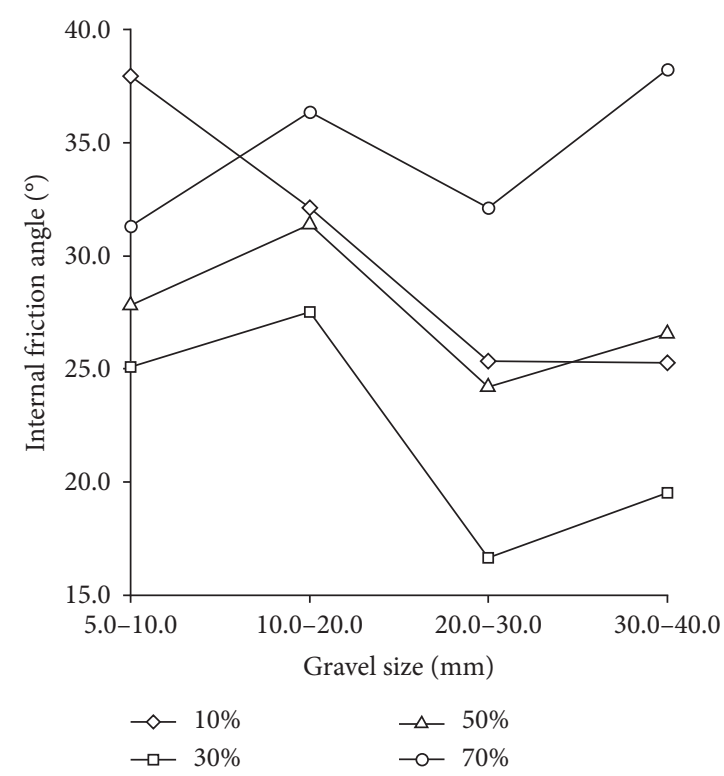

(b)

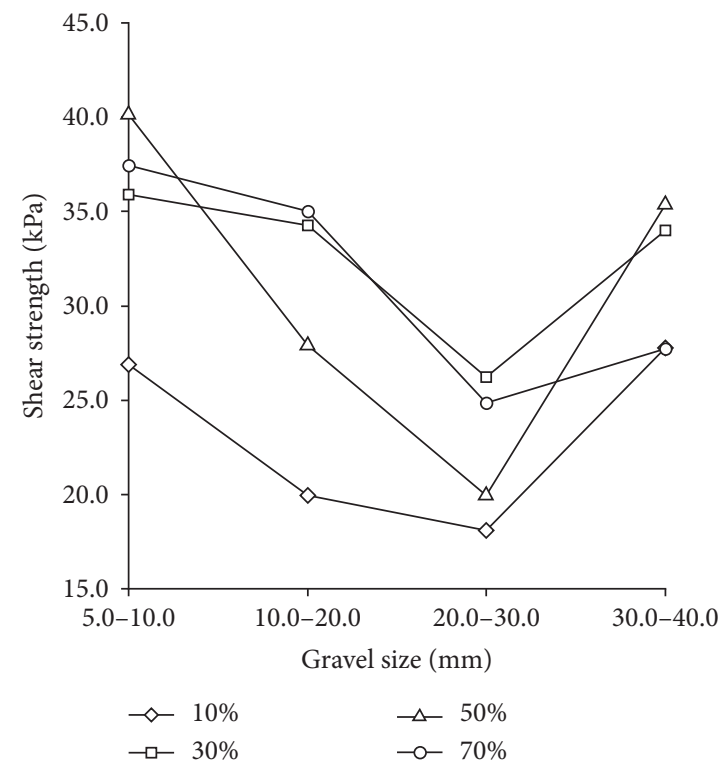

(d)

FIGURE 18: Internal friction angles of the SRM samples with different gravel proportions. (a) SBG for the 1st shear. (b) SBG for the 2nd shear. (c) SBG for the 3rd shear. (d) SSG.

exhibits the shear strength of SRM and gravel size for the SBG and the SSG. According to Figure 19, the shear strength with the gravel size of less than $20-30 \mathrm{~mm}$ presents an increasing trend for the SBG. When the gravel size is greater than $20-30 \mathrm{~mm}$, the shear strength will decrease slightly for the first and second shear experiment. However, for the third shear experiment, the shear strength undergoes little change increasing gravel size. For the SSG, the shear strength of the sample will increase first and then decrease. The specific locations of the stability stage for the gravel size are between $10-20 \mathrm{~mm}$ and $20-30 \mathrm{~mm}$ when the gravel proportion is more than $50 \%$. An analysis of the change law of the shear strength and gravel size demonstrates that cohesion of the sample is affected stronger than the internal friction angle and shear tress by gravel size. The maximum shear strengths can be obtained when the gravel sizes are $20-30 \mathrm{~mm}$, which can be viewed as the optimal gravel size of the SRM. This result can be proved by the aforementioned content regarding the influence of the gravel size on the shear mechanism of the samples.

3.3. Influence of Gravel Shape on Shear Strength. The gravel shape may affect the shear strength of the SRM markedly. However, past research on gravel shape gave no consideration to this factor. Therefore, to study the influence of the 


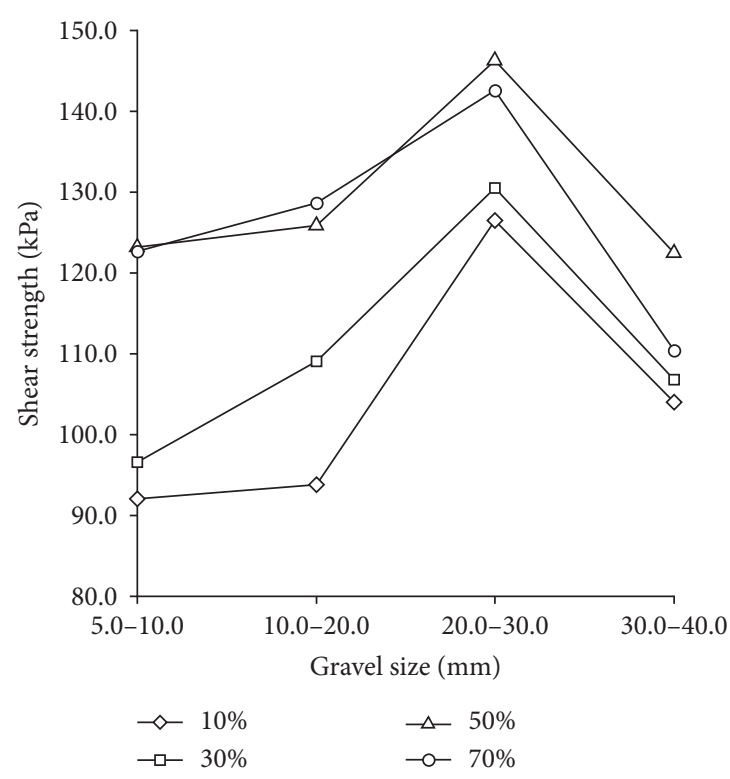

(a)

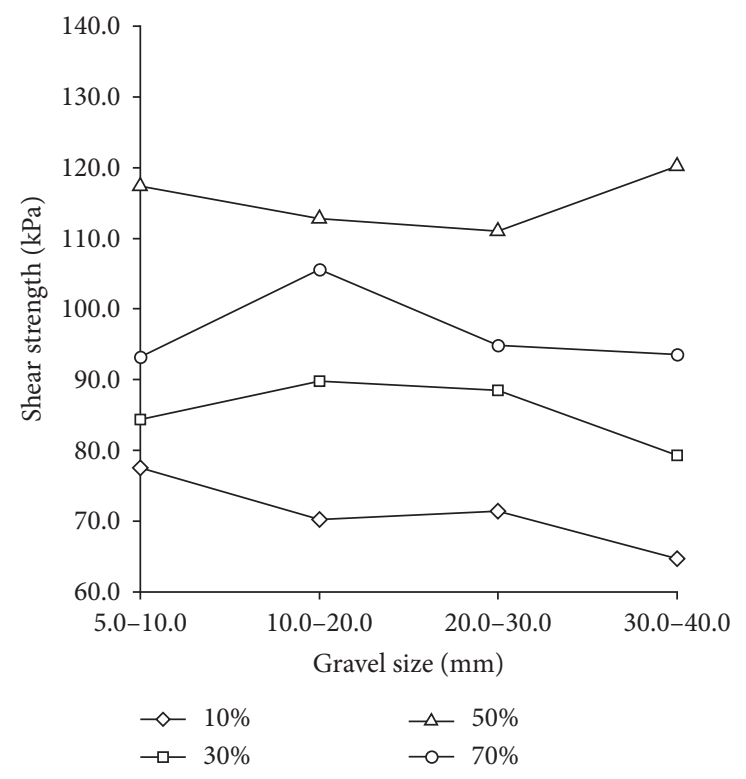

(c)

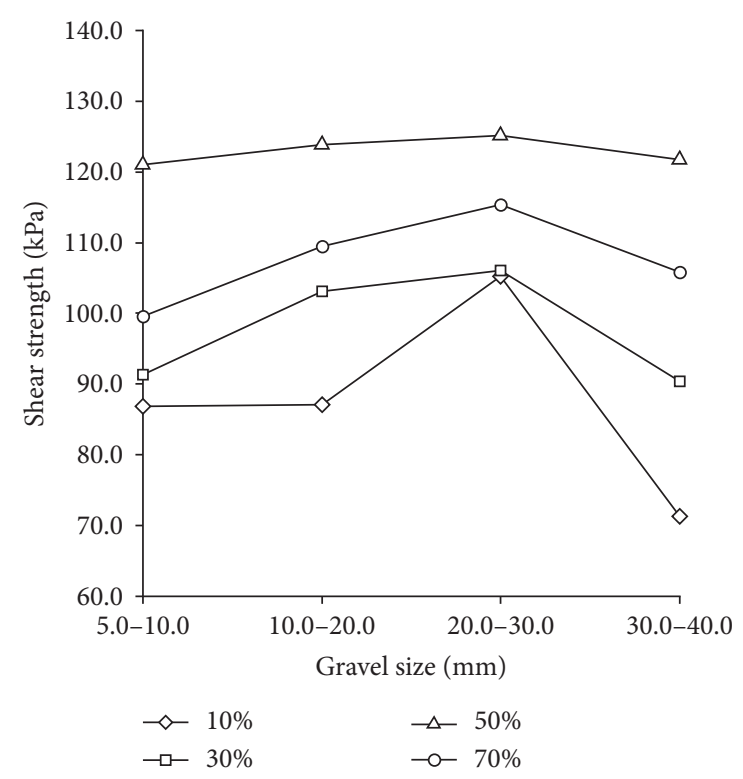

(b)

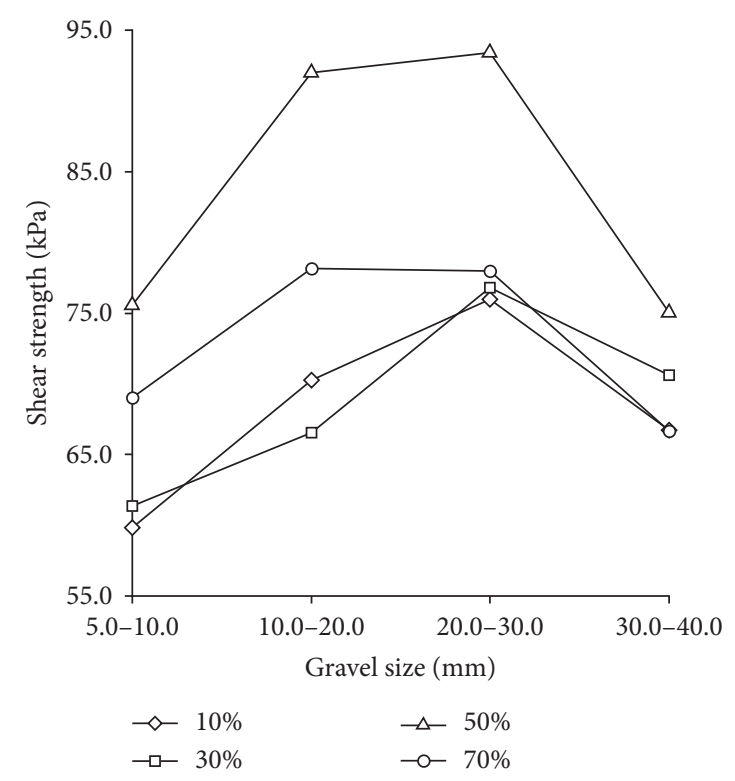

(d)

FIGURE 19: Shear strengths of the SRM samples with different contents of gravel. (a) SBG for the 1st shear. (b) SBG for the 2nd shear. (c) SBG for the 3rd shear. (d) SSG.

gravel shape on the shear strength, the results of the repetitive shear experiment with SBG are compared with those for SSG. Figure 20 indicates the cohesion and gravel proportion for different gravel shapes. The SG represents the subrounded gravel and the BG1 represents the breccia gravel with the first shear experiment.

According to Figure 20, the cohesion of the SBG is far greater than that of the SSG when the gravel size is 5-10 mm. At the same time, the shear times have a significant effect on the cohesion due to the small gravel size. For the gravel size of $10-20 \mathrm{~mm}$, the cohesion of the SSG undergoes a small change with increasing gravel proportion. The cohesion of the SBG presents an increase first, and then a decreasing trend emerges. When the gravel size is greater than $20 \mathrm{~mm}$, the cohesion of the SBG presents a similar change law to that when the gravel size is $5-10 \mathrm{~mm}$. The difference between them arises because the shear strength with the gravel proportion of $70 \%$ of the SSG is greater than that of the SBG. The shear times have some influence in changing the law of cohesion and the gravel proportion but not the value of cohesion. Both the shear times and gravel size will cause the cohesion to trend towards uniformity in value. At the same time, based on Figure 20, it can also be observed that the cohesion of the SBG is far greater than that of the SSG. This indicates that the breccia gravels are important in the shear strength of SBG, and gravels in the sample have been 


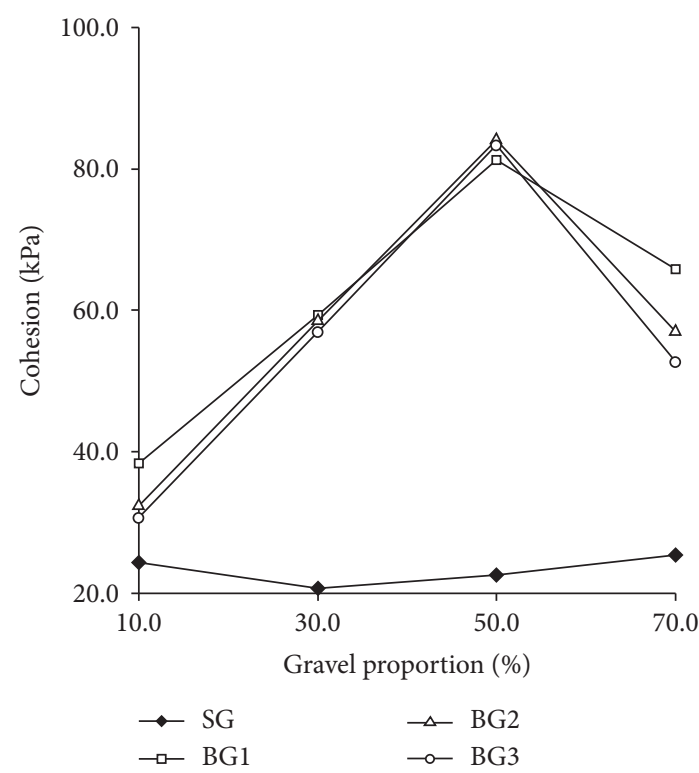

(a)

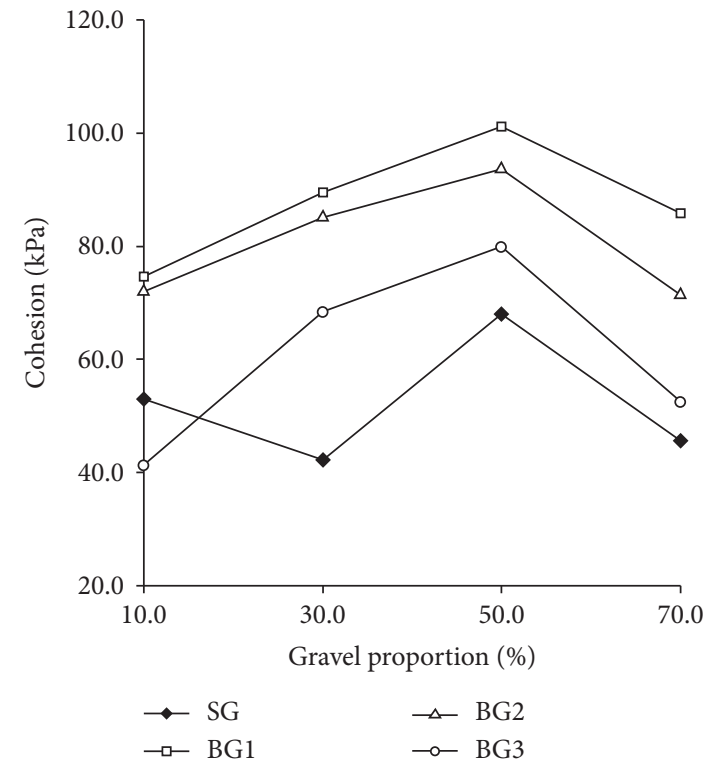

(c)

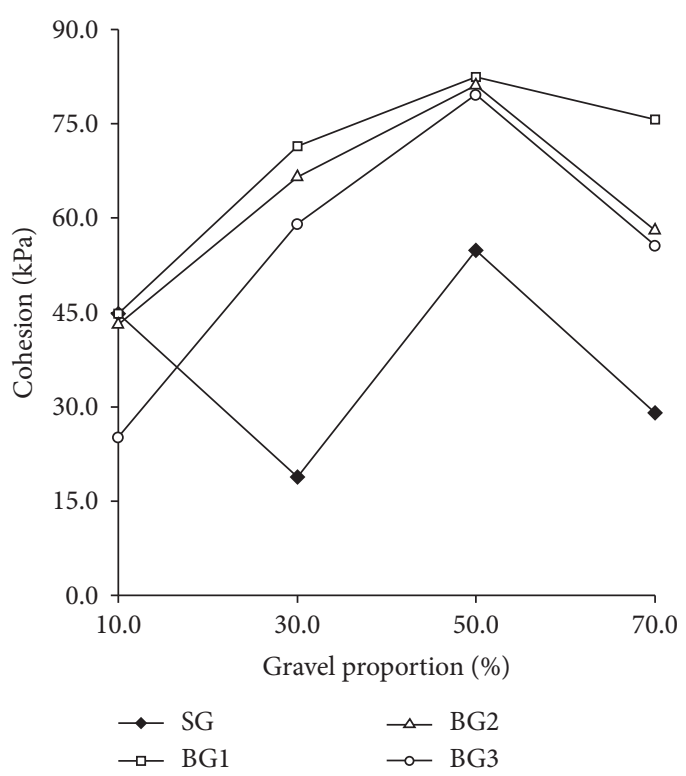

(b)

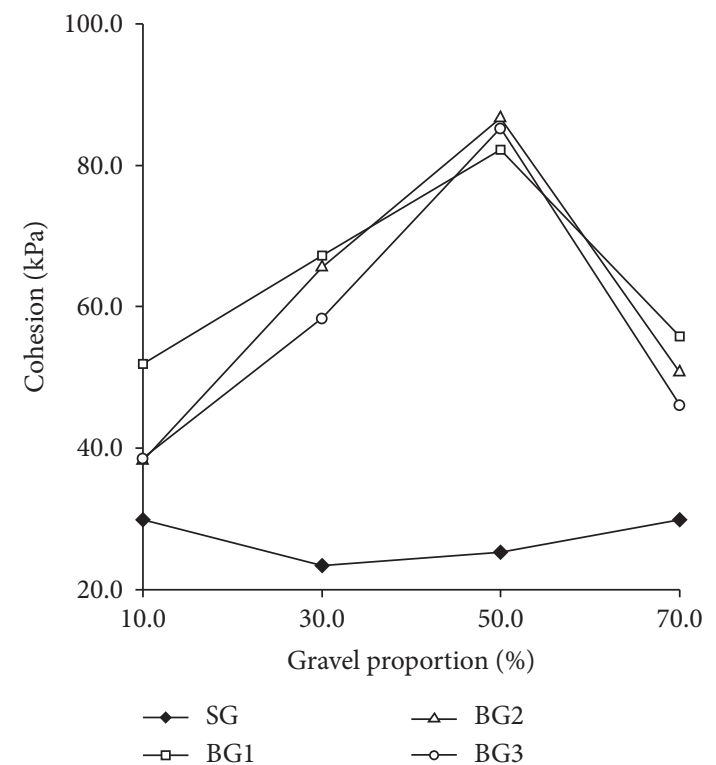

(d)

FIgURE 20: Cohesions of the SRM samples with different gravel shapes. (a) The 1st set samples (gravel size of 5-10 mm). (b) The 2nd set samples (gravel size of $10-20 \mathrm{~mm}$ ). (c) The $3 \mathrm{rd}$ set samples (gravel size of $20-30 \mathrm{~mm}$ ). (d) The 4 th set samples (gravel size of $30-40 \mathrm{~mm})$.

damaged in the process of the shear experiments. The repetitive shear experiments make the gravel shape change gradually from the breccia to the subrounded. The experimental results cause the strength parameters to trend towards uniformity.

Figure 21 indicates the relationship between the internal friction angles of the SRM and the gravel proportion under the different gravel shapes and repetitive shear times. According to Figure 21, when the gravel size is $5-10 \mathrm{~mm}$, the internal friction angle of SBG first decreases and then increases with increasing gravel proportion. In contrast, one of the SSG increases first and then decreases with increasing gravel proportion. This phenomenon can be explained by the fact that small gravels are damaged in the process of the direct shear experiment. For the gravel sizes of $10-20 \mathrm{~mm}$ and $20-30 \mathrm{~mm}$, there is little change law for the internal friction angle of the SBG and SSG. Especially for the SSG, the internal friction angle will be relatively stable when the gravel proportion is over $30 \%$. However, the internal friction angles of the SBG and SSG increase intensely with the gravel proportion being increased when the gravel proportion is greater than $30 \%$. This indicates that the damage of the gravels due to the shear stress or normal stress does not affect the change law of the internal friction angle with the gravel 


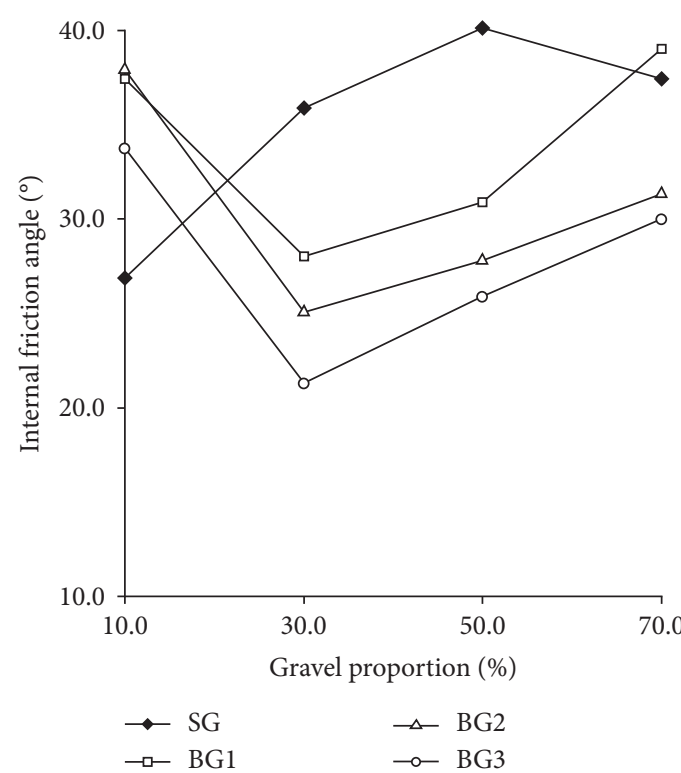

(a)

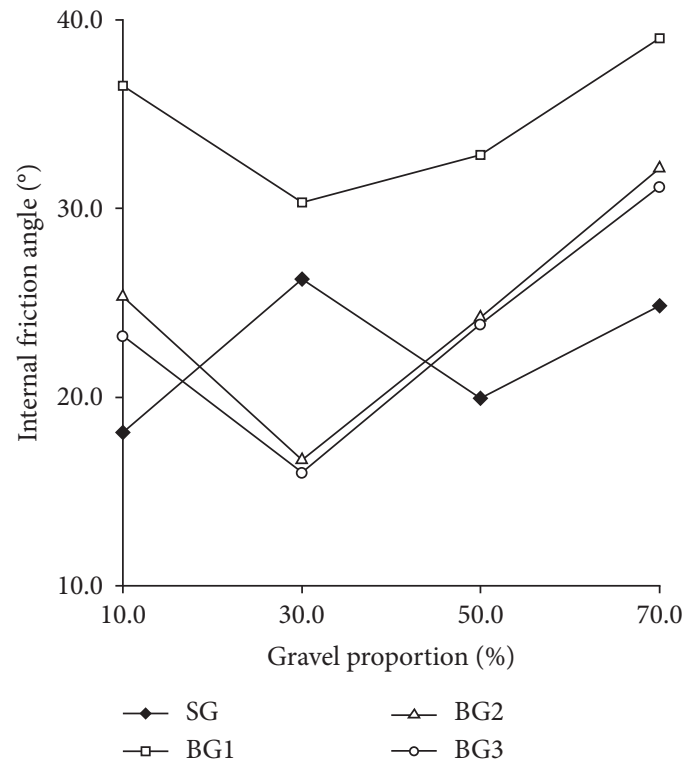

(c)

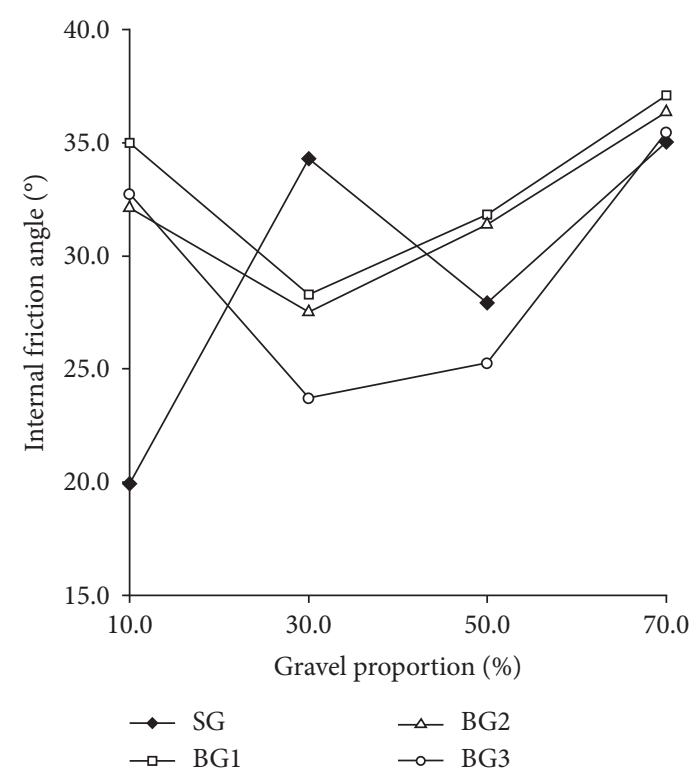

(b)

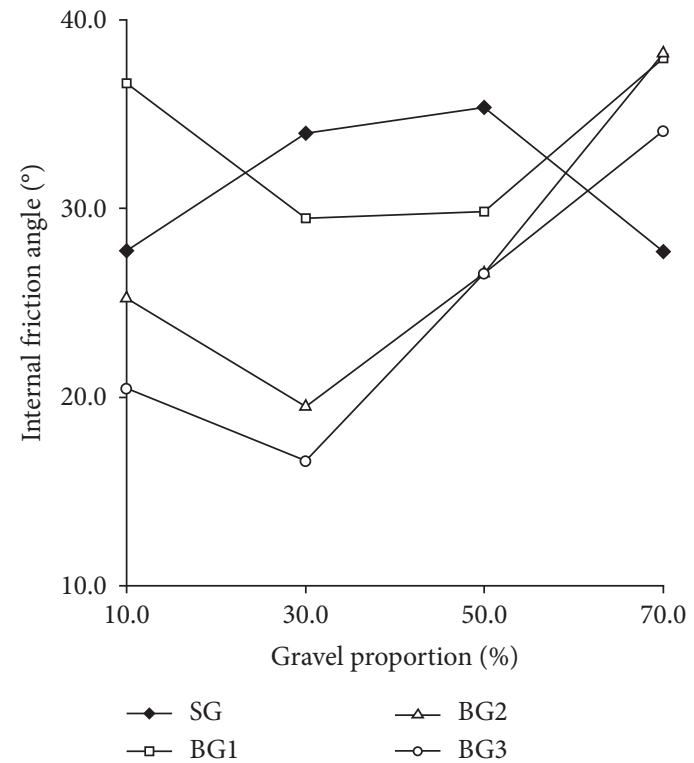

(d)

Figure 21: Internal friction angles of the SRM samples with different gravel shapes. (a) The 1st set samples (gravel size of 5-10 mm). (b) The 2nd set samples (gravel size of 10-20 mm). (c) The 3rd set samples (gravel size of 20-30 mm). (d) The 4th set samples (gravel size of 30-40 mm).

proportion being increased. Based on Figure 21, internal friction angle of the first time is greater than those of the second and third time. The internal friction angle will approach each other with the shear times increasing. In contrast, the internal friction angle for the SSG will exhibit a decreasing trend when the gravel proportion is $>50 \%$.

Figure 22 indicates the relationship between shear strength with gravel proportion under different gravel shapes. To study the overall influence of the gravel shape on shear strength, the Mohr-Coulomb criterion with the normal stress of $70 \mathrm{kPa}$ is selected to calculate the shear strength. According to Figure 22, shear strength of the SSG is less than that of the SBG even if the SBGs are sheared three times. The shear strength for the different gravel sizes will obtain the maximum value at a gravel proportion of $50 \%$. Shear strength of the SBG and the SSG will exhibit a decreasing trend when the gravel proportion is $>70 \%$.

\subsection{Influence of the Repetitive Shear Process on Shear Strength.} Figure 23 demonstrates the relationship between the cohesion and the shear times under the different gravel sizes and gravel proportions. The cohesion of the SBG decreases gradually with increasing shear times and that of the SBG 


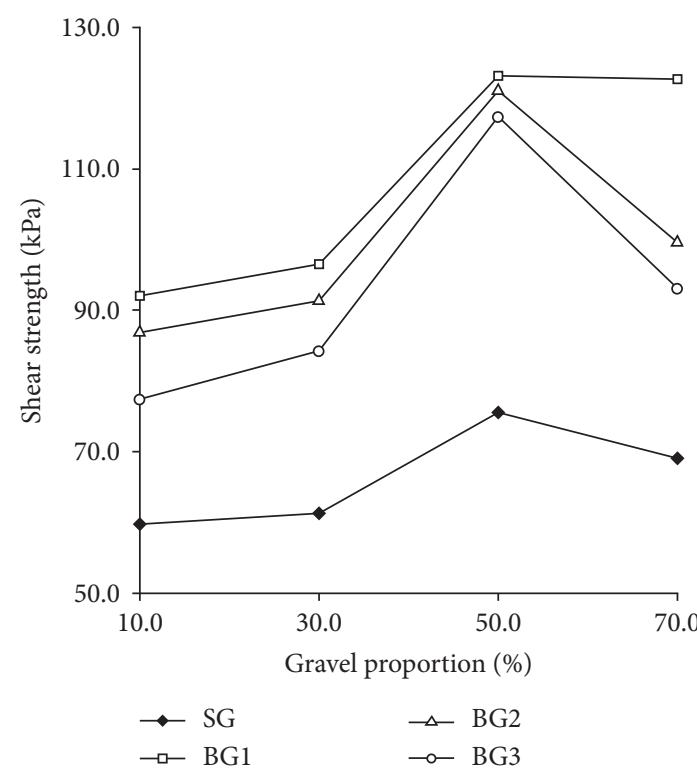

(a)

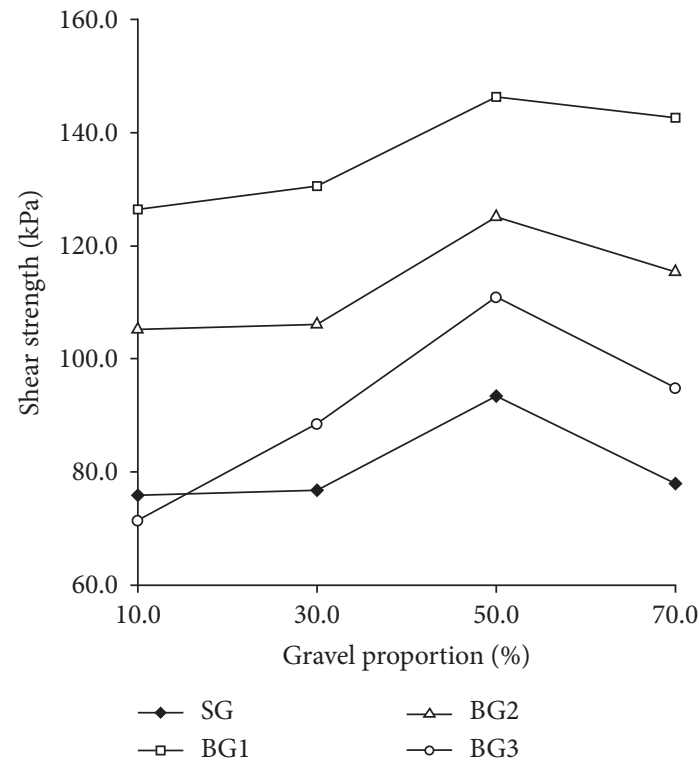

(c)

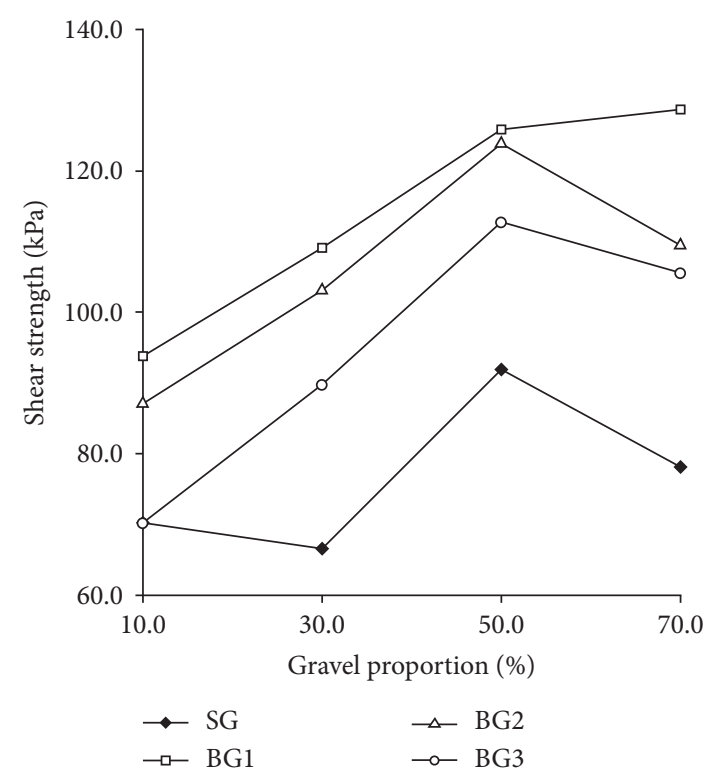

(b)

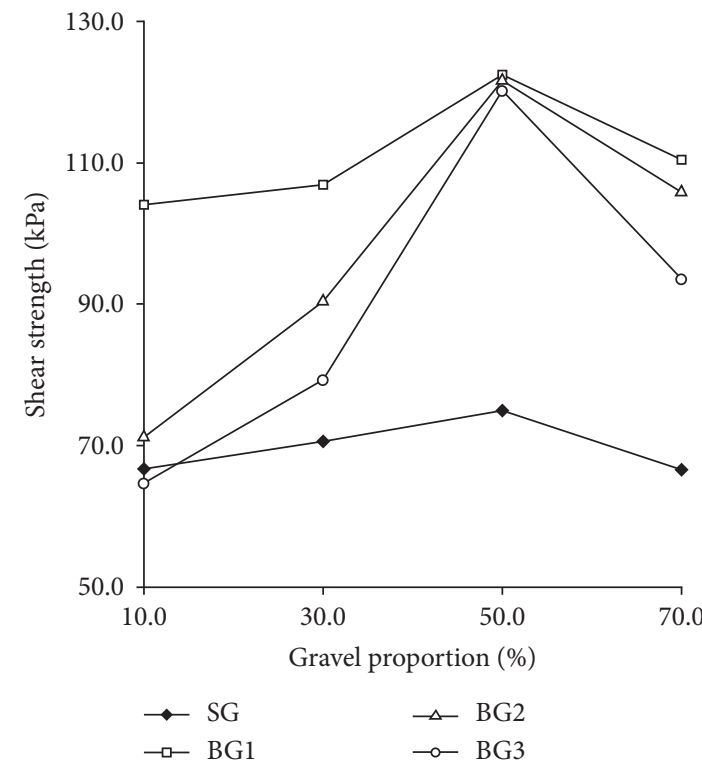

(d)

Figure 22: Shear strengths of the SRM samples with different gravel shapes. (a) The 1st set samples (gravel size of 5-10 mm). (b) The 2nd set samples (gravel size of 10-20 mm). (c) The 3rd set samples (gravel size of 20-30 mm). (d) The 4th set samples (gravel size of 30-40 mm).

with a gravel proportion of $50 \%$ and grain size of $30-40 \mathrm{~mm}$ will increase with the increasing shear times. Under the low gravel proportion and a gravel size of $10-20 \mathrm{~mm}$, the cohesion decreases markedly, and the cohesions of the other samples have a similar change law with the shear times increasing. When the gravel size is greater than $20-30 \mathrm{~mm}$, the cohesions of the majority of the SBG present a decreasing trend with increasing shear times. The change of the cohesion is related to the gravel proportion and undergoes a minimal change in the shear times when the grain sizes are low.

Figure 24 exhibits the internal friction angle with shear times under the different gravel sizes and the gravel proportions. According to Figure 24, it can be observed that the entire change trend of internal friction angle with the shear times decreases. Based on the SRM with the anisotropic inhomogeneous properties, a slightly increasing trend may emerge. The internal friction angle of the SBG with the different gravel proportions presents a marked decreasing trend. When the gravel sizes are 20$30 \mathrm{~mm}$ and $30-40 \mathrm{~mm}$, especially for the latter, the internal friction angle will decrease markedly for the first shear times. The internal friction angle will decrease slowly with shear times.

The anisotropy and inhomogeneity of the SRM can cause the different change laws of the shear strength 


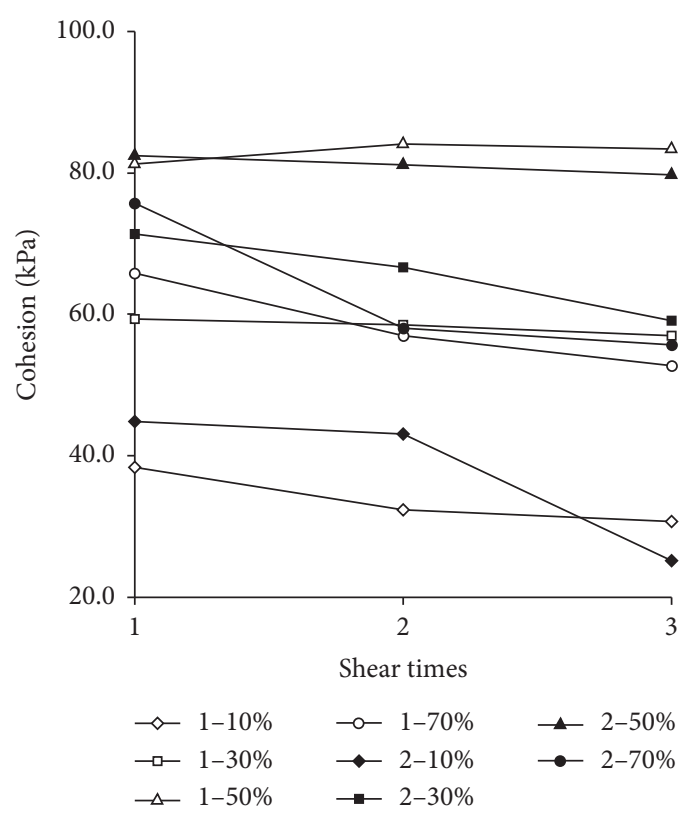

(a)

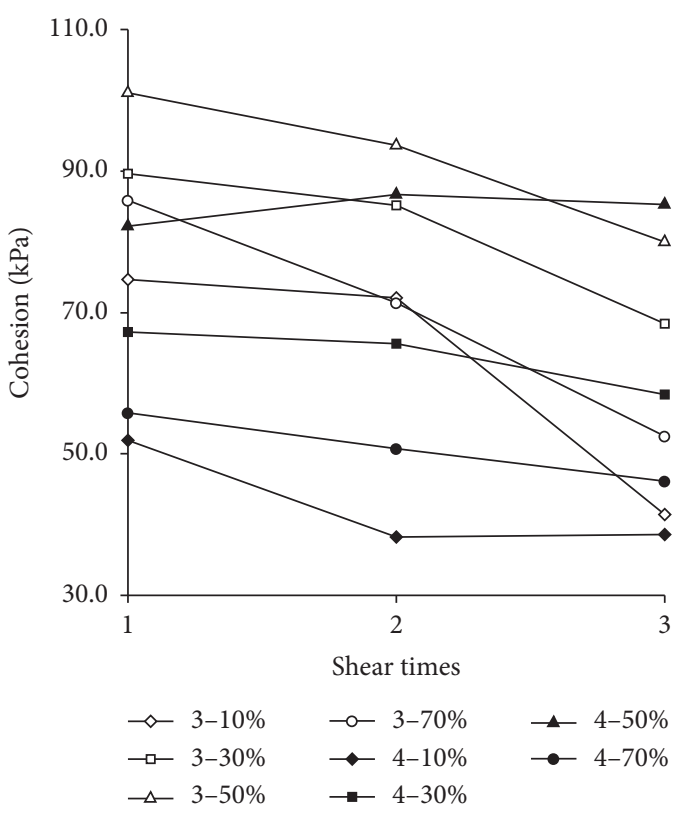

(b)

FIgURE 23: Cohesions of the SRM samples with different sets and gravel proportions. (a) The 1st set and the 2nd set. (b) The 3rd set and the 4th set.

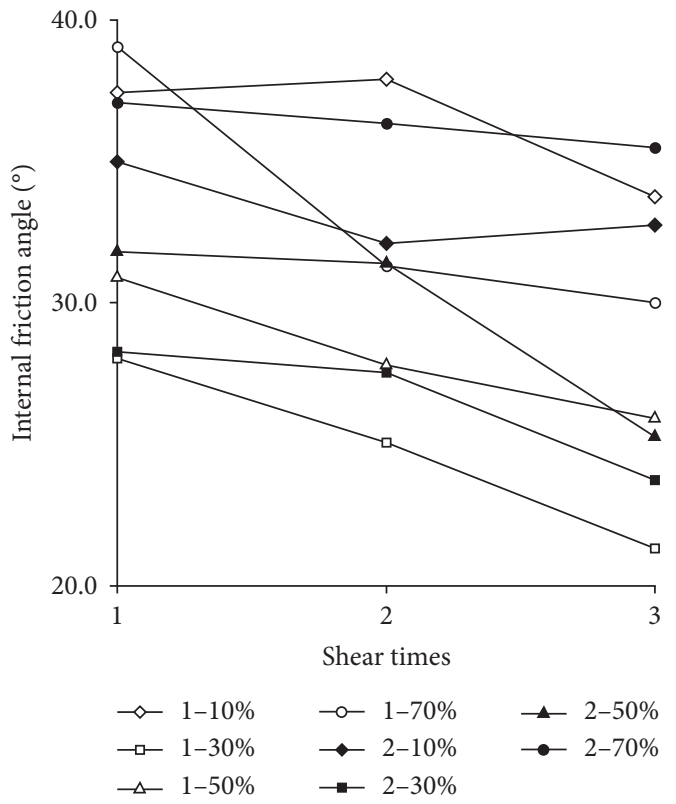

(a)

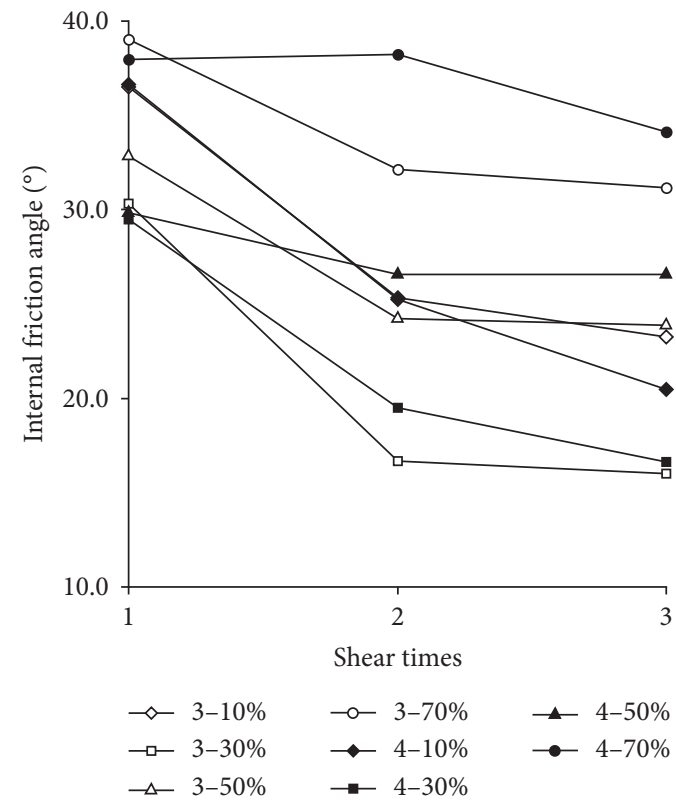

(b)

FIGURE 24: Internal friction angles of the SRM samples with different sets and gravel proportions. (a) The 1st set and the 2nd set. (b) The 3rd set and the 4th set.

parameters. So, to evaluate the influence of the shear times, the overall shear strength of the SRM is selected. Figure 25 exhibits the relationship between the shear strength and the shear times under the different gravel sizes and gravel proportions. According to Figure 25, the shear strength of the SBG presents a decreasing trend with increasing shear times. The repetitive shear experiment causes a marked decrease in the shear strength of the SRM. With respect to the same sample, the shear strength parameters present a decreasing trend with increasing shear times, especially for the shear strength. In addition, the influence of the repetitive shear experiment on the internal friction angle is greater than that of the cohesion and shear strength. 


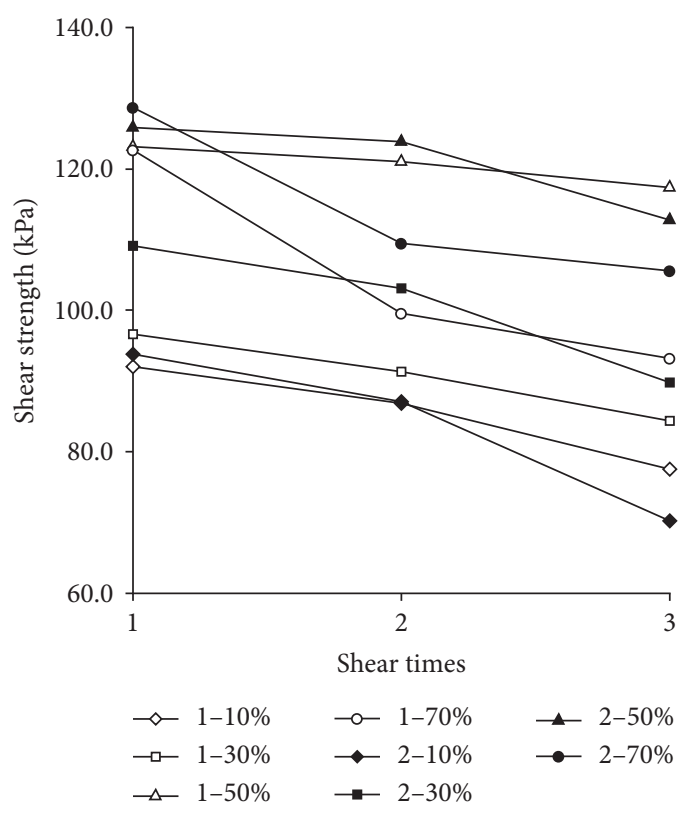

(a)

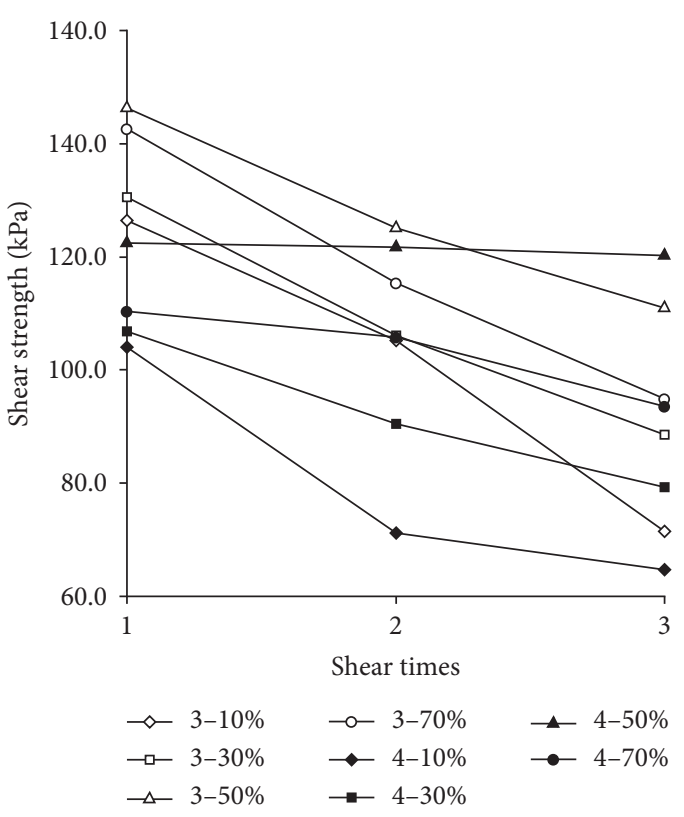

(b)

FIGURE 25: Shear strengths of the SRM samples with different sets and gravel proportions. (a) The 1st set and the 2nd set. (b) The 3rd set and the 4 th set.

\section{Conclusions}

By using the laboratory direct shear experiment, certain influencing factors, which are the gravel proportion, the gravel size, the gravel shape, and the repetitive shear process, are considered in analyzing the shear failure mechanism of the SRM. Based on the experimental results, the curve of shear stress with horizontal displacement is divided into four stages, which include the pressure dense phase, the linear phase, the elastic and plastic phase, and the creep phase. Generally, the shear stress of the SRM increases with the increasing gravel proportion. However, when the gravel proportion is too high (for example, 70\%), the value of the shear stress depends on the gravel shape and the distribution in space and not completely on the gravel proportion. Under the same gravel proportion, the shear stress does not present a monotonous increasing trend with the increased gravel size but presents an increase to a decrease. The maximum shear strength is obtained when gravel size reaches the "optimal gravel size". The optimal gravel size is $50 \%$ based on the results from the laboratory experiments. At the same time, the gravel shape is another factor that influences the shear strength of the SRM, because the gravel shape determines the contact pattern among the gravels and the failure mechanism of the SRM. Obviously, the shear strength of the SBG is far more than that of the SSG. The repetitive experiment has proved that the breccia gravel in the SRM can be damaged with the shear times increasing and the breccia gravel become subrounded gravel after several repetitive shear experiments.

For the same gravel sizes, the shear strength parameters of the SRM present an increasing trend with the gravel proportion increasing. The increasing degree of the cohesion and shear strength is larger than that of the internal friction angle. However, shear strength parameters exhibit a decreasing trend when the gravel proportion reaches $70 \%$. Under the same gravel proportion, the shear strength parameters fail to exhibit a monotonous increasing or decreasing trend. The maximum shear parameters are obtained with the gravel size between $10-20 \mathrm{~mm}$ and $20-30 \mathrm{~mm}$. That is, the optimal gravel size of the SRM in this experiment is $20 \mathrm{~mm}-30 \mathrm{~mm}$. Generally, the gravel shape is the main factor for the internal friction angle. Meanwhile, the gravel shape has a great influence on the cohesion. The reason is that the special contact pattern between the breccia gravel and the fine grain soil is important to the cohesion. The results of the repetitive shear experiment prove that the shear strength of SRM decreases gradually with the shear times increasing. The essence of the repetitive shear experiment is to judge the influence degree of the gravel shape on the shear strength parameters between SBG and SSG. The results indicate that shear strength of SBG becomes gradually closer to that of the SSG when the shear times reach a certain degree.

\section{Data Availability}

The data used to support the findings of this study are available from the corresponding authors upon request.

\section{Conflicts of Interest}

The authors declare that they have no conflicts of interest.

\section{Acknowledgments}

This project was supported by the National Natural Science Foundation of China (nos. 41672258 and 41102162) and 
Postgraduate Research \& Practice Innovation Program of Jiangsu Province (no. KYCX17_0501), which is greatly appreciated. This research was also supported by the Fundamental Research Funds for the Central Universities (no. 26120172017B665X14).

\section{References}

[1] X. H. You, "Stochastic structural model its application of the SRM," Doctor thesis, Northern Jiaotong University, Beijing, China, 2001.

[2] E. Medley, The engineering characterization of mélanges and similar block-in-matrix rocks (bimrocks), Ph.D. dissertation, University of California, Oakland, CA, USA, 1994.

[3] F. Lanaro and P. Tolppanen, "3D characterization of coarse aggregates,” Engineering Geology, vol. 65, no. 1, pp. 17-30, 2002.

[4] X. Li, Q. L. Liao, and J. M. He, "In situ tests and a stochastic structural model of rock and soil aggregate in the three gorges reservoir area, China," International Journal of Rock Mechanics and Mining Sciences, vol. 41, no. 3, pp. 494-495, 2004.

[5] N. Zhao, Y. C. Wang, B. Meng, and N. Luo, "Numerical simulation on the seepage properties of soil-rock mixture," Advances in Civil Engineering, vol. 2018, Article ID 1859319, 10 pages, 2018.

[6] A. K. H. Kwan, C. F. Mora, and H. C. Chan, "Particle shape analysis of coarse aggregate using digital image processing," Cement and Concrete Research, vol. 29, no. 9, pp. 1403-1410, 1999.

[7] J. M. He, "Deformation and failure mechanism of the SRM in the three gorges reservoir area," Doctor thesis, China University of Mining and Technology, Beijing, China, 2004.

[8] W.-J. Xu, Z.-Q. Yue, and R.-L. Hu, "Study on the mesostructure and mesomechanical characteristics of the soil-rock mixture using digital image processing based finite element method," International Journal of Rock Mechanics and Mining Sciences, vol. 45, no. 5, pp. 749-762, 2008.

[9] W. J. Xu and R. L. Hu, "The concept, classification and significance of SRM," Hydrogeology and Engineering Geology, vol. 4, pp. 50-56, 2009.

[10] Y. X. Zhao and Z. X. Liu, "Study of material composition effects on the mechanical properties of soil-rock mixtures," Advances in Civil Engineering, vol. 2018, Article ID 3854727, 10 pages, 2018.

[11] X. Z. Chen, "Experimental study on strength and bite force of coarse grained soil," Engineering Mechanics, vol. 11, no. 4, pp. 56-62, 1994.

[12] Q. G. Guo, Engineering Properties and Application of CoarseGrained Soil, Yellow River Water Conservancy and Hydropower Press, Zhengzhou, China, 1998.

[13] E. A. Miller and G. F. Sowers, "The strength characteristics of soil-aggregate mixtures," Highway Research Board Bulletin, vol. 183, pp. 16-23, 1957.

[14] A. S. Patwardhan, J. S. Rao, and R. B. Gaidhane, "Interlocking effects and shearing resistance of boulders and large size grains in a matrix of fines on the basis of large scale direct shear tests," in Proceedings of the 2nd Southeast Asian Conference One Soil Mechanics, pp. 265-273, Indian Institute of Technology, Singapore, June 1970.

[15] J. P. Savely, "Determination of shear strength of conglomerates using a caterpillar D9 ripper and comparison with alternative methods," International Journal of Mining and Geological Engineering, vol. 8, no. 3, pp. 203-225, 1990.
[16] M. Wu, "Experimental study on mechanical properties of non-homogeneity SRM filling," Road, vol. 1, pp. 40-49, 1997.

[17] G. L. Huang, J. Zhou, and X. N. Gong, "Stress-strain and shear strength properties of rock and soil materials of waste pile in open pit mines," Journal of Zhengjiang University, vol. 34, no. 1, pp. 54-58, 2000.

[18] S. L. Han, H. X. Zhou, and R. S. Chen, "The creep tests of soil and crushed stone mixture," Chinese Journal of Geotechnical Engineering, vol. 21, no. 3, pp. 196-199, 1999.

[19] M. H. Ren, G. S. Zhao, X. H. Qiu, Q. H. Xue, and M. T. Chen, "A systematic method to evaluate the shear properties of soilrock mixture considering the rock size effect," Advances in Civil Engineering, vol. 2018, Article ID 6509728, 9 pages, 2018. 


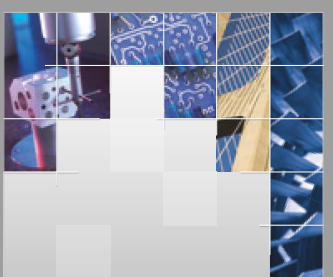

\section{Enfincering}
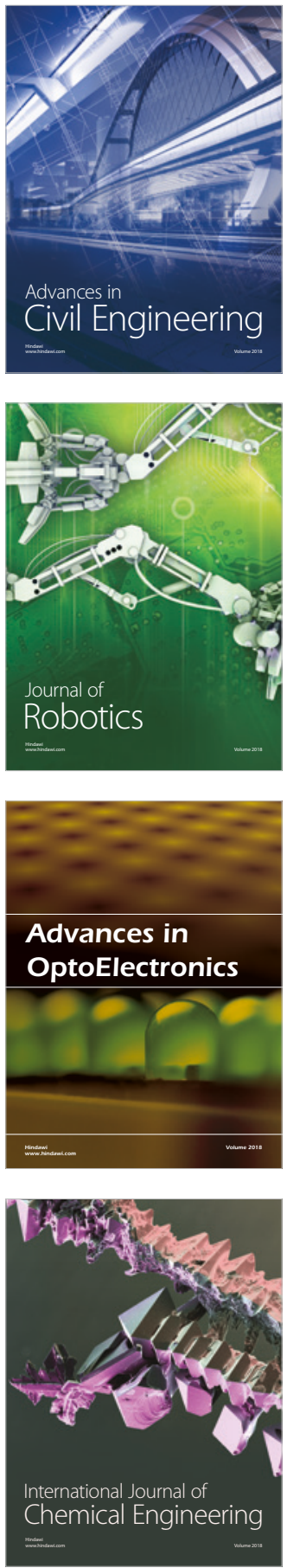

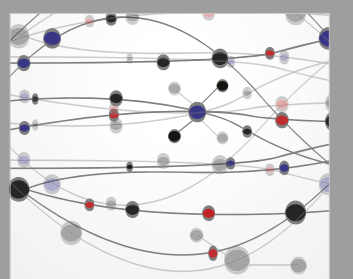

\section{Rotating \\ Machinery}

The Scientific World Journal

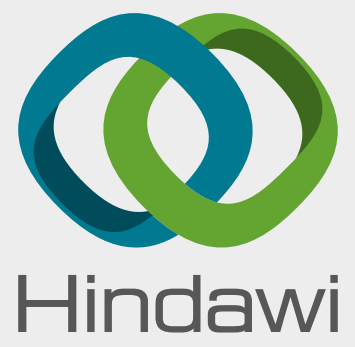

Submit your manuscripts at

www.hindawi.com
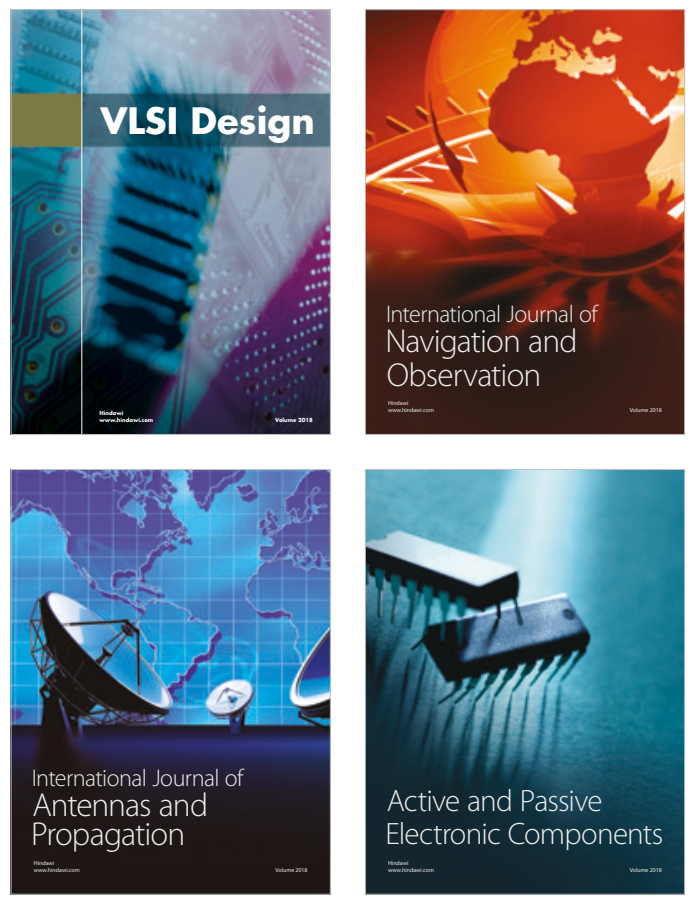
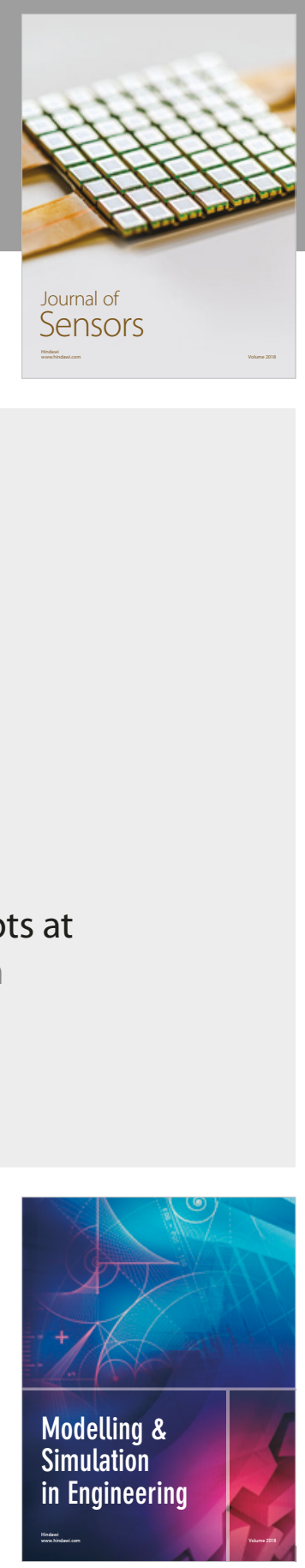

\section{Advances \\ Multimedia}
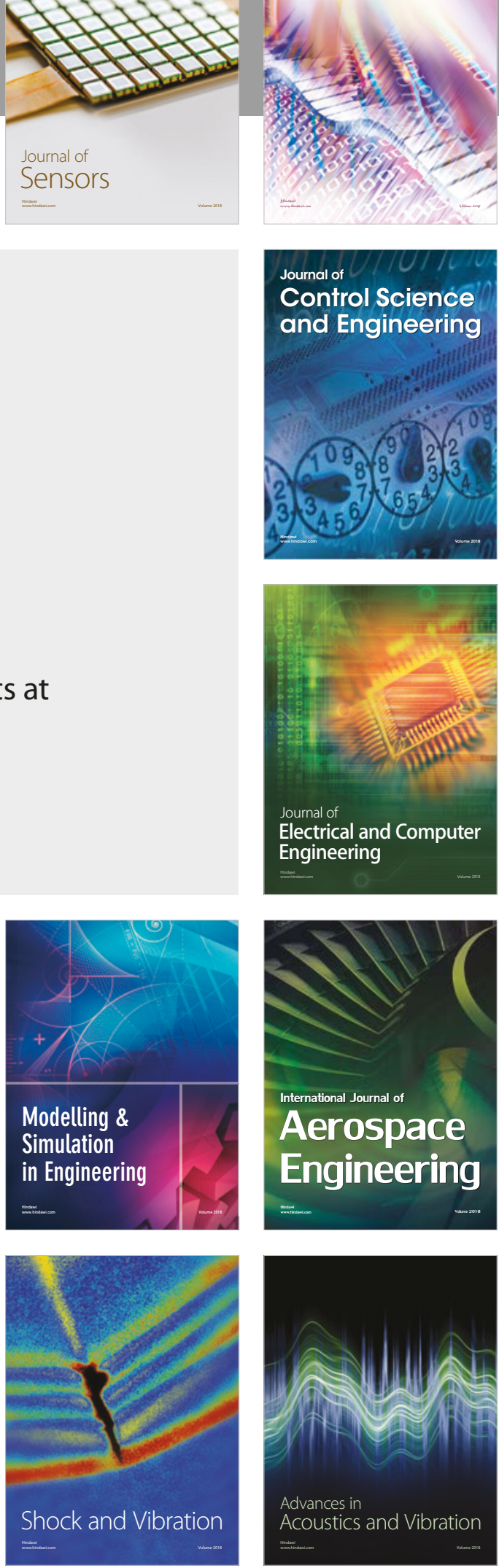